\title{
Bone mineral density, polyphenols and caffeine: a reassessment
}

\author{
T. P. Dew, A. J. Day and M. R. A. Morgan* \\ Procter Department of Food Science, University of Leeds, Leeds LS2 9JT, UK
}

\begin{abstract}
Several studies have shown beneficial associations between tea consumption and bone mineral density (BMD) and fracture risk. Current investigations into potential mechanisms of benefit are focused upon the F and polyphenol components of tea. However, previous studies have pointed towards caffeine consumption as a potential risk factor for low BMD and high fracture risk. Tea, therefore, represents an interesting paradox as a mildly caffeinated beverage that may enhance bone health. Fruit and vegetable intake has also been associated with BMD, and it is now apparent that several fruit and vegetable components, including polyphenols, may contribute positively to bone health. Evidence surrounding the function(s) of polyphenol-rich foods in bone health is examined, along with more recent studies challenging the relevance of caffeine consumption to in vivo $\mathrm{Ca}$ balance. Plant foods rich in polyphenols such as tea, fruit and vegetables, as significant factors in a healthy diet and lifestyle, may have positive roles in bone health, and the negative role of caffeine may have been overestimated. The present review covers evidence of dietary mediation in positive and negative aspects of bone health, in particular the roles of tea, fruit and vegetables, and of caffeine, flavonoids and polyphenols as components of these foods. Since the deleterious effects of caffeine appear to have been overstated, especially in respect of the positive effects of flavonoids, it is concluded that a reassessment of the role of caffeinated beverages may be necessary.
\end{abstract}

Bone health: Flavonoids: Polyphenols: Caffeine

\section{Introduction}

In an ageing Western society, the treatment of ageprogression diseases (cancer and heart disease, for example) has become a major issue. Similarly, the maintenance of good bone health with age becomes increasingly important. In osteoporosis, bone becomes increasingly porous, resulting in both greater chance and severity of bone fracture at the hip, spine, forearm and shoulder ${ }^{1}$. Bone fractures can mean reduced mobility, discomfort and a higher risk of early mortality. Osteoporosis can also pressure society as a whole, with the estimated annual cost to the UK of hip fracture alone exceeding $£ 1.7$ billion $^{2}$. The sum is likely to increase as life expectancy increases and the medical options extend. Elderly women are the prime demographic group at risk from osteoporosis, because they can lose between 10 and $15 \%$ of their bone every 10 years after the menopause $\mathrm{s}^{3}$. The reasons for this are that women tend to have lower peak bone mass than men, and that levels of oestrogen (a hormone with a positive effect on bone health) are decreased during and after menopause. However, the consequences of the hormonal changes occurring during pregnancy and because women tend to live longer than men are factors that complicate the issue.

Bone tissue is in a constant state of flux. As well as the various mechanical roles performed by the skeleton (Table 1), it must also act as a $\mathrm{Ca}$ depository for the rest of the body, with $\mathrm{Ca}$ being removed and replaced as required. The state of bone flux within an individual can be described in terms of bone mineral density (BMD). Bone metabolism is controlled by a variety of growth hormones, sex steroid hormones (such as oestrogens), thyroxine, corticosteroids and insulin. However, three hormones play vital roles - 1,25-dihydroxycholecalciferol, parathyroid hormone and calcitonin $^{4}$. As well as affecting dietary $\mathrm{Ca}$ adsorption efficiencies, these hormones also influence the three cell types relevant to bone formation and metabolism (Fig. 1): osteoblasts (bone formation), osteocytes (bone maintenance) and osteoclasts (bone resorption). Imbalances in bone metabolism can cause either improper bone formation or accelerated bone loss 5 . The balance between the formation and resorption of bone tissue is affected by genetic and environmental (for example, diet and lifestyle) factors.

\footnotetext{
Abbreviations: BMC, bone mineral concentration; BMD, bone mineral density; EGCG, epigallocatechin gallate; FN, femoral neck; HRT, hormone replacement therapy; LS, lumbar spine; ppm, parts per million.

* Corresponding author: Professor Mike Morgan, fax +44 113343 2982, email m.morgan@food.leeds.ac.uk
} 
Table 1. Roles of calcium and calcium balance in bone health

\begin{tabular}{|c|c|c|}
\hline & $\begin{array}{c}\text { Approximate distribution } \\
\text { of total body } \mathrm{Ca}(\%)\end{array}$ & $\begin{array}{c}\text { Typical } \\
\text { roles of } \mathrm{Ca} \text { in vivo }\end{array}$ \\
\hline Bone tissue (skeleton, etc) & 99 & $\begin{array}{l}\text { Supports and protects other organs } \\
\text { Site for blood cell production } \\
\text { Combines with muscle and connective tissue to enable mobility }\end{array}$ \\
\hline Rest of body & 1 & $\begin{array}{l}\text { A wide range of cellular reactions, including: } \\
\text { Blood clotting } \\
\text { Neurotransmitter secretion } \\
\text { Normal nerve conduction } \\
\text { Neuromuscular system and muscle contraction } \\
\text { Some enzyme-mediated reactions } \\
\text { Structural role in organelles and membranes }\end{array}$ \\
\hline
\end{tabular}

The importance of diet to bone health is well established. However, recent evidence from both epidemiological and experimental studies would suggest that links between diet and bone health go beyond the scope of adequate nutrition (i.e. sufficient $\mathrm{Ca}$ and vitamin $\mathrm{D}$ ), with non-nutrient food components (for example, polyphenols) also playing a role. It is not within the scope of the present review to provide an all-inclusive detailing of the field of diet and bone health. Indeed throughout the text, where appropriate, the reader is directed to comprehensive works of other authors. It is the purpose of the present review, rather, to highlight the evidence indicating a need for a reassessment of traditional perceptions surrounding tea, caffeine, fruit and vegetables with regard to bone health.

\section{Tea and bone health}

A growing body of evidence suggests that tea consumption might be beneficial with regard to BMD.

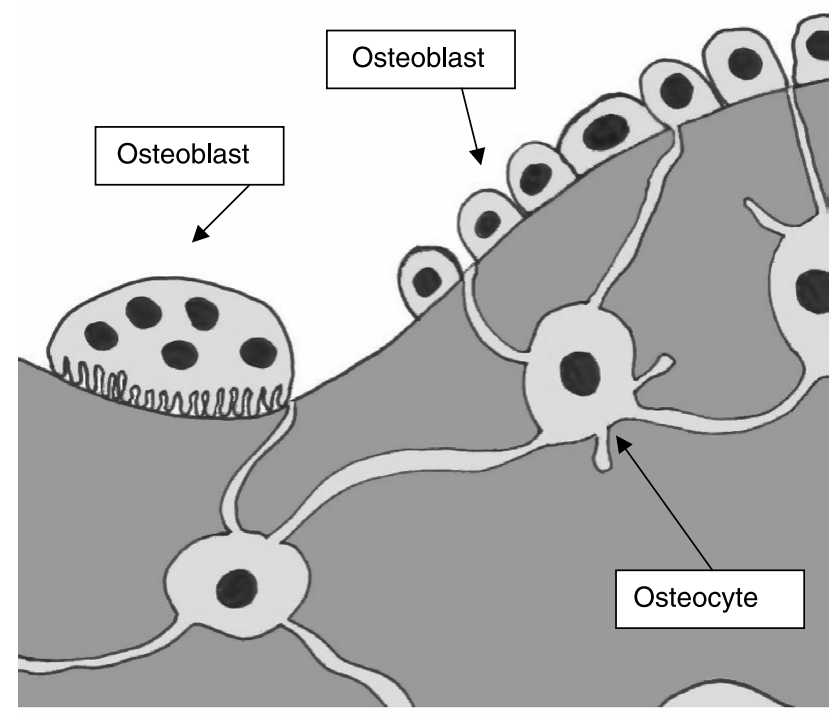

Fig. 1. Principal cell types relevant to bone formation and metabolism: osteoblasts (bone formation), osteocytes (bone maintenance) and osteoclasts (bone resorption).

\section{Epidemiological studies}

Several studies have been performed showing the association between tea drinking and BMD. For example in the Mediterranean Osteoporosis Study (MEDOS), Johnell et al. ${ }^{6}$ found that the consumption of tea was associated with a significantly decreased risk of fracture in a cohort of women aged over 50 years from southern Europe. Whilst in the UK and Ireland black tea is frequently consumed with milk, meaning that tea drinkers have increased $\mathrm{Ca}$ intake, in most other countries (including those of the MEDOS cohort), black tea is consumed without milk ${ }^{7}$. It is therefore possible that tea may benefit bone health beyond the provision of extra $\mathrm{Ca}$ from added milk.

In studying a cohort of sixty-two postmenopausal women who had not received hormone replacement therapy (HRT), Hoover $e t a l .{ }^{8}$ found that of all dietary factors measured tea consumption was most strongly (and positively) related to lumbar and femoral (Fig. 2) bone density, whilst Ca intake and absorption failed to show a statistically significant relationship to overall bone density (once adjusted for relationships between bone density and number of years since menopause, body weight and lean body mass), although a significant relationship did persist when femoral BMD was taken alone.

Similarly, a study of 1256 British women aged between 65 and 76 years $^{9}$ found that BMD at all sites tested was considerably higher in tea drinkers compared with non-tea drinkers. The relationship remained significant in three out of four sites after adjustment for factors such as BMI and age, and was independent of smoking status, use of HRT, coffee consumption and the addition of milk to tea (except at the greater trochanter, where BMD values were higher in those that added milk to tea compared with black tea drinkers and non-tea drinkers). However, the relationship between tea consumption and BMD was independent of the volume of tea consumed on a daily basis. Less than $10 \%$ of the cohort were non-tea drinkers, and so it is possible that this relatively small sub-population was not representative of non-tea drinkers in the wider UK population in terms of BMD. Coffee was consumed by $81 \%$ of tea drinkers and $88 \%$ of non-tea drinkers. No significant relationship between tea consumption and coffee consumption was found.

In addition to the evidence above, it should also be remembered that the amount of milk added to tea is often very small. Typically, $25 \mathrm{ml}$ (whole) milk is present in a $190 \mathrm{ml}$ cup of tea ${ }^{10}$. Given whole milk has an average 


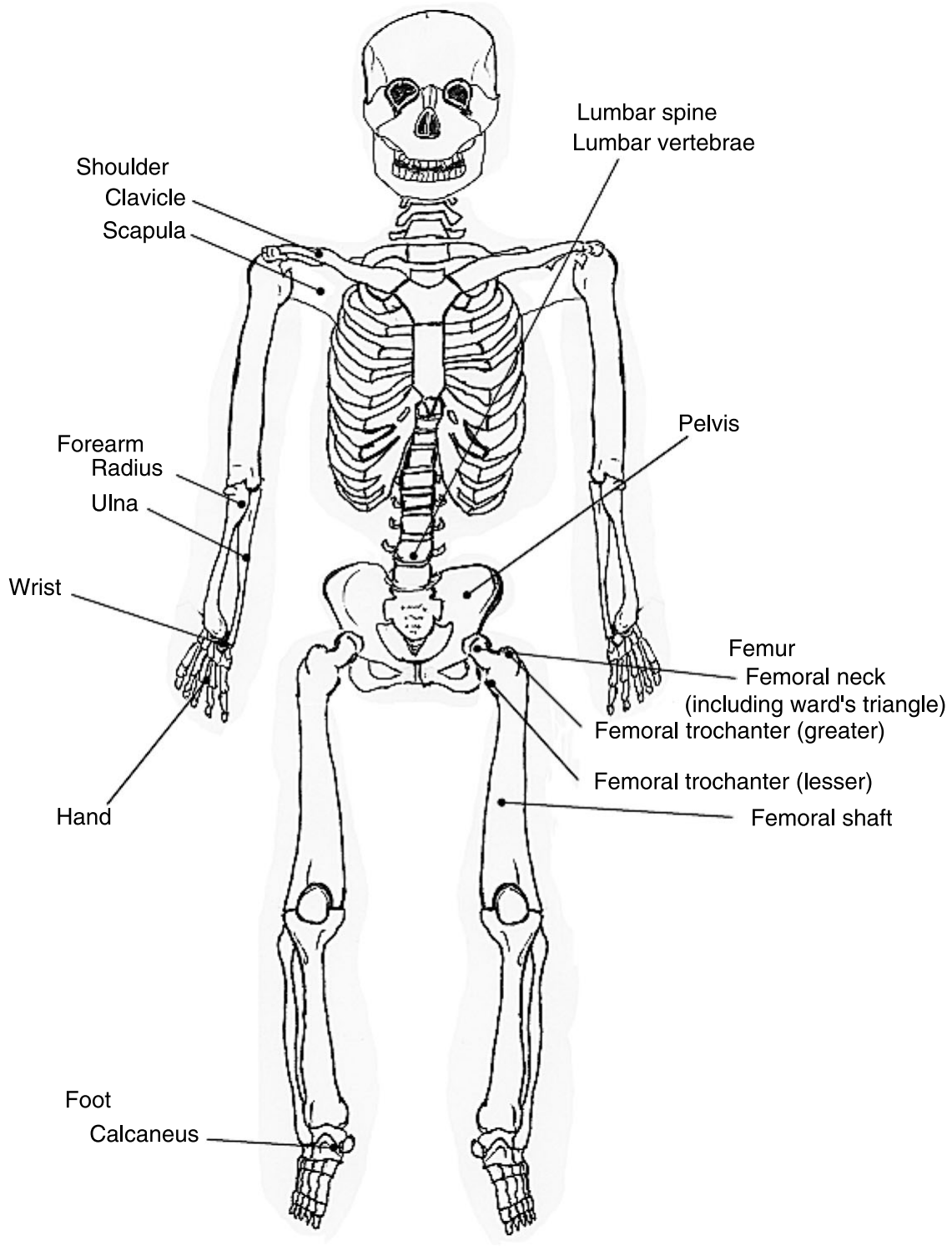

Fig. 2. Common skeletal regions pertinent to bone-health research.

Ca content of $120 \mathrm{mg}$ per $100 \mathrm{ml}^{11}$, one cup of tea provides just $30 \mathrm{mg} \mathrm{Ca}-$ just over $4 \%$ of the $700 \mathrm{mg}$ reference nutrient intake for men and women. Tea is therefore unlikely to be a significant dietary source of $\mathrm{Ca}$ except in those with particularly poor diets, or unless copious volumes are consumed daily.

It is possible that the BMD-related advantages of tea drinking are cumulative, with benefits being proportional to habit length. For example, in a study of 1037 men and women aged over 30 years ${ }^{12}$, those that had habitually drunk tea for 6-10 years had significantly higher lumbar spine (LS) BMD compared with non-habitual tea drinkers, whilst those with a habit exceeding a decade had higher BMD at four separate sites compared with other groups. The relationship held after adjustment for other confounding factors, with tea consumption predicting $0 \cdot 5-5 \cdot 1 \%$ variation in BMD. No significant difference in BMD was shown between non-habitual drinkers and those with 1-5 years of habit. No significant difference could be found between those drinking black tea (9\%) and those drinking green or oolong tea $(91 \%)$. However, it was suggested that the number of black tea drinkers in the study may have been too small to significantly represent BMD. Importantly, the study used a group in which only ninety-six individuals out of 502 habitual tea drinkers (19\%) added milk to tea.

It is also possible that various types of tea may confer beneficial effects on BMD. Muraki et al. ${ }^{13}$ showed in a study of 655 Japanese women over the age of 60 years that consumption of green tea on $>5 \mathrm{~d} /$ week was associated with a significantly higher BMD compared with those consuming green tea less frequently. The relationship was independent of biometric confounding factors, diet, exercise, and use of tobacco, alcohol and treatments for osteoporosis. However, as $91.6 \%$ of women studied fell into the high consumption classification, it is possible that infrequent tea drinkers were under-represented. 


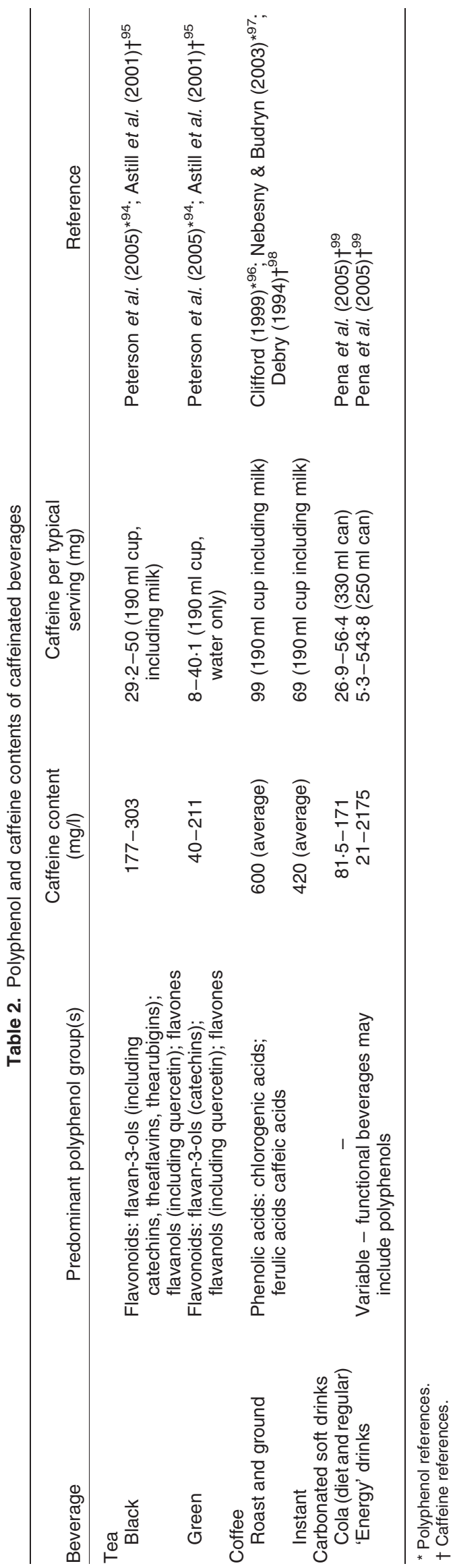

In a study of 2016 postmenopausal women ${ }^{14}$ tea consumption (unspecified type) was shown to have a protective effect in the femoral neck (FN) region, but not the spinal region. However, an inverse relationship between tea and coffee intake $(r-0.38 ; P<0.001)$ was also found. Chen $\mathrm{et} \mathrm{al} .{ }^{15}$ found a similarly inverse trend between tea and coffee drinking in a cohort of postmenopausal women from the USA. Therefore as Vestergaard et al. ${ }^{14}$ suggest, the apparent benefits of tea consumption may simply be an index of low coffee (and thus lower caffeine) intake (Table 2).

Not all epidemiological studies show direct associations between tea consumption and bone health. For example, Chen et al. ${ }^{16}$ found that tea drinking was not significantly associated with BMD in postmenopausal women from the USA. However, tea consumption was positively related to total body and spinal BMD in women who either used HRT or had used HRT in the past, leading to the suggestion that HRT and tea consumption may have a synergistic effect upon BMD. It is possible, however, that women receiving HRT are associated with different lifestyles to those not undergoing treatment and tea consumption and HRT may not be interacting directly. In a later study, Chen et al. ${ }^{15}$ found that whilst tea consumption was significantly and positively related to total body $\operatorname{BMD}(P<0.05)$ in a subgroup of 4979 women from the USA (aged 50-79 years), Cox proportional hazard models (accounting for various confounding factors) showed no significant relationship between tea consumption and risk of hip or wrist or forearm fracture in the overall cohort of 91465 women. Chen et al. ${ }^{15}$ concluded that the effect of habitual tea drinking upon BMD was small and did not affect the risk of fracture in the population studied.

\section{Putative mechanisms relating tea to bone mineral density}

It is likely that the benefits to bone health of tea consumption go beyond the provision of extra $\mathrm{Ca}$ from added milk. Therefore, the effects of tea upon BMD are the result of one or more components of tea infusion. Whilst the mechanism(s) for such effects remain to be established, several have been proposed.

Fluorine and positive bone health. F occurs as salts (fluorides) in vivo, becoming incorporated into bone mineral by substituting for the hydroxyl group in hydroxyapatite to form fluorapatite, thus increasing overall stability ${ }^{17}$. Fluoride has also been shown to stimulate the formation of new bone and can inhibit or reverse dental carries, and fluoride has been used either alone or combined with $\mathrm{Ca}$, vitamin $\mathrm{D}$ or oestrogen to treat osteoporosis ${ }^{18}$. Most fresh foods contain just 0.01-1 parts per million (ppm) fluoride ${ }^{18}$, though fish and tea are exceptions. Whilst no RDA value for fluoride intake has been suggested, $10 \%$ of UK drinking water is fortified with fluoride to a level of $1 \mathrm{ppm}$, primarily to benefit dental health.

In a study of several teas, Fung et al. ${ }^{19}$ reported a variety of fluoride contents for different tea types infused in doubledistilled water at $1 \%(\mathrm{w} / \mathrm{v})$ for $5 \mathrm{~min}$ (Table 3). From the results of Fung et al. ${ }^{19}$ the average fluoride content of black teas from Sri Lanka (Twinings) and the UK (Lipton and Rickshaw) was $0.93 \mathrm{mg} / \mathrm{l}$ tea liquor (reaching $1.5 \mathrm{mg} / \mathrm{l}$ upon 
Table 3. Fluorine content of $1 \%$ tea infusions (adapted from Fung et al. ${ }^{19}$ )

\begin{tabular}{llc}
\hline Tea type & $\begin{array}{c}\text { Region or } \\
\text { country of } \\
\text { origin }\end{array}$ & $\begin{array}{c}\text { Dissolvable } \\
\mathrm{F} \text { in tea liquor } \\
(\mathrm{mg} / \mathrm{l})\end{array}$ \\
\hline Chinese green & $\begin{array}{l}\text { Zhejiang } \\
\text { Guangdong }\end{array}$ & 1.22 \\
Chinese oolong & Guangdong & 1.20 \\
& Guangdong & 1.18 \\
Chinese pureh & Yunnan & 0.82 \\
& Yunnan & 0.59 \\
Chinese black & Yunnan & 0.58 \\
& Yunnan & 0.90 \\
Twinings (black) & Guangdong & 1.13 \\
Lipton (black) & Yunnan & 0.94 \\
Rickshaw (black) & Sunnan & 1.02 \\
Chinese brick & Englank & 1.25 \\
& England & 1.35 \\
& Hunan & 0.91 \\
& Hunan & 0.94 \\
& & 0.93 \\
\end{tabular}

infusion for $360 \mathrm{~min}$ ), which equates to $0.15 \mathrm{mg}$ fluoride per cup. Similarly, Duckworth \& Duckworth ${ }^{20}$ investigated the F contents of tea samples taken from fifty selected UK households. On each of 3 consecutive days, consumption data (via questionnaire) and an infused tea sample were obtained. Fluoride concentrations of tea samples (made with drinking water containing $<0.15 \mathrm{ppm}$ fluoride) varied widely from 0.44 to $2.78 \mathrm{mg}$ per litre tea liquor $(0.07-0.46 \mathrm{mg} / \mathrm{cup})$. The authors calculated that daily intake of fluoride from tea ranged from 0.04 to $2.71 \mathrm{mg} / \mathrm{d}$, and that daily intake increased with age (mean daily intakes ranged from $0.3 \mathrm{mg}$ for those below 7 years, to $0.85 \mathrm{mg}$ for those above 60 years). However, the authors stated that the small size of each age group (the study used 213 subjects in total) denies any extrapolation of consumption trends to the greater UK population.

Fluorosis. However, the dose gap between activity and toxicity for fluoride is narrow ${ }^{17}$ and excessive consumption of fluoride can lead to a condition termed 'fluorosis'. Doses in excess of $8 \mathrm{mg} / \mathrm{d}^{17}$ can lead to bone diseases such as osteosclerosis (an abnormal hardening or increased density of bone) and osteoporosis, and calcification of ligaments and tendons resulting in joint pain, stiffness, muscle impairment and eventual abnormalities of the spine, legs and $\operatorname{arms}^{21}$.

Tea drinking has been associated with fluorosis in certain geographical areas of the world. For example, Cao et al. ${ }^{22}$ reported that consumption of 'brick tea' (low-quality tea leaves, pressed into blocks) was the major cause of fluorosis in the Tibetan province of Naqu County. Foods containing brick tea accounted for $99 \%$ of the daily intake of fluoride (reaching $12 \mathrm{mg}$ in adults), with $89 \%$ of the 111 randomly sampled adults (male and female, aged 30-78 years) studied showing clinical symptoms of fluorosis. Similarly, Zhang et al. ${ }^{23}$ found that bone mass was significantly lower at the calcaneus (measured using quantitative ultrasound analysis) and in both the dominant and non-dominant hands (measured using metacarpal cortical index) in women from a grassland area ( $n$ 38) compared with those in an urban area ( $n$ 46) within Inner Mongolia. High fluoride concentrations of brick tea $(2.61-10.87 \mathrm{ppm})$ were significantly correlated to dominant and non-dominant hand metacarpal cortical index in the grassland group. In an earlier paper Cao et al. ${ }^{24}$ stated that educating populations with a long history of brick tea consumption may do little to change their consumption habits, suggesting instead that the provision of a lowfluoride substitute tea may be a better approach to reducing the occurrence of fluorosis. Rats given a low-fluoride brick tea rather than a normal brick tea $(210 \mathrm{mg}$ soluble fluoride per $\mathrm{kg}$ dried tea v. $503.5 \mathrm{mg} / \mathrm{kg}$ respectively), were observed to have no signs of dental fluorosis after 1 year, compared with a $75 \%$ incidence in the group consuming normal brick tea. The authors suggested that a low-fluoride brick tea is likely only to prevent development of fluorosis rather than reverse the condition.

Associations between tea and fluorosis are mainly restricted to the consumption of brick tea in areas where the diets of the populations are much more restricted than those of Western populations. For example, the Tibetans living at high altitude in the study of Cao et $a .^{22}$ did not have access to vegetables, gaining much of their energy from buttered tea and zamba (tea mixed with fried highland barley flour). However, an incident of skeletal fluorosis has recently been linked to high consumption of instant teas in the USA ${ }^{25}$, in which four out of ten preparations tested had fluoride levels exceeding the $2.4 \mathrm{ppm}$ upper limit for bottled beverages (as set by the US Food and Drug Administration), with one preparation exceeding the $4 \mathrm{ppm}$ safety limit for drinking water as set by the US Environmental Protection Agency. Nevertheless, whilst excessive consumption of tea will always bring the risk of fluorosis, it is suggested that the risk to Western populations is relatively small.

Flavonoids. Tea is a rich source of flavonoids which may benefit bone density both through the inhibition of bone resorption and the stimulation of bone growth. The predominant flavonoids within tea are catechins. Green tea typically contains $32-40 \%$ catechins by dry weight, whilst black tea contains $10-12 \%$ catechins $^{26}$. Epigallocatechin gallate (EGCG) is the major catechin, accounting for between 9 and $13 \%$ of green tea on a dry weight basis. Tea (both green and black) also contains significant quantities of flavonols, methylxanthines (for example, caffeine), organic acids and volatiles. It contains a number of complex polyphenols such as thearubigins and theaflavins, and is also the only known source of the non-essential amino acid theanine. Several studies concerning the use of tea flavonoids as potential therapeutic agents for osteoporosis have been performed. Fig. 3 shows the structures of certain tea flavonoids and other relevant polyphenols.

Flavonoids: effects on bone health. Catechins have been shown to affect bone metabolism both in vitro and in vivo. For example, pre-treating calvaria (from embryonic mice) with (+)-catechin $(0 \cdot 1-1 \mathrm{~mm})$ resulted in a dose-dependent inhibition of bone resorption after addition of parathyroid hormone in vitro ${ }^{27}$. In the same study, a similar pretreatment with $(+)$-catechin $(0.8 \mathrm{mM})$ was shown to inhibit bone resorption caused by the addition of $\mathrm{PG} \mathrm{E}_{2}$ or retinoic acid. Addition of (+)-catechin $(0.8 \mathrm{~mm})$ to calvaria 
(A)<smiles>Cn1c(=O)c2c(ncn2C)n(C)c1=O</smiles>

(B)<smiles>Oc1cc(O)c2c(c1)OC(c1ccc(O)c(O)c1)C(O)C2</smiles>

(C)<smiles>O=C(O[C@H]1Cc2c(O)cc(O)cc2OC1c1cc(O)c(O)c(O)c1)c1cc(O)c(O)c(O)c1</smiles>

(D)<smiles>O=C1C(c2ccc(O)cc2)=CCc2cc(O)cc(O)c21</smiles>

(E)<smiles>O=c1c(O)c(-c2ccc(O)c(O)c2)oc2cc(O)cc(O)c12</smiles>

( $\mathrm{F})$

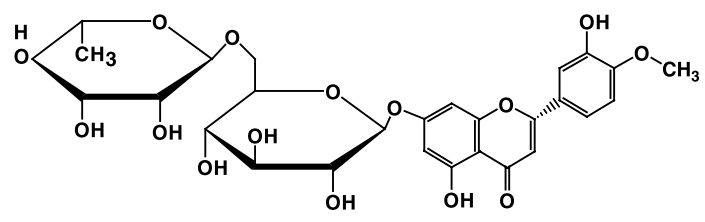

Fig. 3. Structures of particular compounds pertinent to bone health. (A) Caffeine (an alkaloid found in coffee, tea and mate); (B) catechin (a flavan-3-ol found in tea); (C) epigallocatechin gallate (a flavan-3-ol found in tea); (D) genistein (an isoflavone found glycosylated in soya and soya products along with related phyto-oestrogens daidzein, glycetein, formononetin and biochanin A); (E) quercetin (a flavonol found glycosylated in onions, tomatoes and tea); (F) hesperidin (hesperetin 7-rhamnoglucoside, a flavanone glycoside found in citrus fruits).

pre-treated with either parathyroid hormone or retinoic acid was also shown to inhibit resorption of bone.

Polyphenols (including catechin, epicatechin and EGCG) were shown to influence the proliferation of osteoblasts in cell culture in vitro over a wide range of concentrations $(0 \cdot 001 \mathrm{nM}$ to $10 \mu \mathrm{M})$. At low concentration, osteoblast proliferation was increased. The polyphenols tested also stimulated the generation of osteoclasts at low concentration.
However, upon increasing polyphenol concentration, catechin and EGCG were shown to decrease osteoclast generation $^{28}$. In the same study, green tea extracts $(0 \cdot 0016-0 \cdot 2 \mu \mathrm{l} / \mathrm{ml})$ were also shown to inhibit the generation of osteoclasts in cell culture in a dose-dependent manner and increased the proliferation and activity of osteoblasts at low concentrations (although proliferation and activity were decreased at higher concentrations).

Similarly, various catechins were shown to reduce levels of osteoclast cells without affecting levels of osteoblasts in vitro ${ }^{29}$. The most potent of the catechins was EGCG, which induced apoptosis in over $90 \%$ of osteoclasts when present at $100 \mu \mathrm{M}$. Apoptosis was shown to be induced by increasing protease (specifically caspase) activity. However, as the addition of a synthetic pan-caspase inhibitor (z-ValAla-Asp-xxfluoromethyl ketone) only partially suppressed EGCG-mediated apoptosis but completely inhibited the activation of caspase, it was suggested that other pathways to EGCG-mediated cell death may exist. Nakagawa et al. ${ }^{29}$ went on to show that the EGCG-mediated activation of caspase was through the reduction of $\mathrm{Fe}_{(\text {III) }}$ to $\mathrm{Fe}$ (II), which could in turn take part in the Fenton reaction, thus increasing oxidative stress (Fig. 4).

Catechin has also been shown to increase the viability of osteoblastic MC3t3-E1 cells in a dose-dependent manner over a range of $1 \mathrm{~nm}-1 \mathrm{~mm}^{30}$. Treatment with catechin $(0.1 \mathrm{~mm})$ increased alkaline phosphatase activity (an indicator of osteoblastic activity) and reduced osteoblastic apoptosis induced by the addition of $0.001 \mu \mathrm{M}-\mathrm{TNF}-\alpha$. Interestingly, catechin was also shown to reduce the secretion of cytokines involved in osteoclast formation and bone resorption (TNF- $\alpha$ and IL-6) by MC3t3-E1 cells.

In rats exposed to $\mathrm{Cd}$ over 20 weeks (in order to increase bone resorption and thus decrease $\mathrm{BMD}^{31}$ ), urinary deoxypyridinoline (an index of bone resorption):creatinine ratios were increased in those consuming a catechin-free diet, or a diet containing just $0.25 \%$ catechin. However, in rats fed a diet containing larger doses of catechin $(0.5 \%)$, urinary deoxypyridinoline:creatinine ratios were similar to that of the control group. Supplementation with catechin resulted in rises of total BMD values similar to that of the control group, with non-supplemented rats showing a $10 \%$ lower rise in BMD. Total bone mineral concentration (BMC) increases were $60 \%$ lower in the non-supplemented group, with catechin-supplemented rats experiencing similar rises in BMC values to the control group in all bone types tested except for vertebra (which were still lower than control). Total bone Ca showed similar trends to BMC. It was thus concluded that catechin normalised BMD, BMC and bone $\mathrm{Ca}$ content in rats poisoned with $\mathrm{Cd}$. In contrast, Takita et $\mathrm{al}^{32}$ found that EGCG implanted into rats caused increased cartilage formation and decreased bone formation. EGCG was shown to decrease angiogenesis and osteogenesis but increase chondrogenesis.

The tea flavonoid rutin and its aglycone quercetin (Fig. 3) have also been shown to modulate the activity of bone cells in vitro and in vivo. During an $11 \mathrm{~d}$ incubation, both rutin and quercetin (10 nM) significantly inhibited the formation of osteoclasts in porcine bone marrow cells treated with 1,25-dihydroxyvitamin $\mathrm{D}_{3}(10 \mathrm{~nm})^{33}$. In the same study, a $48 \mathrm{~h}$ treatment of $11 \mathrm{~d}$ old osteoclast cells with rutin or 


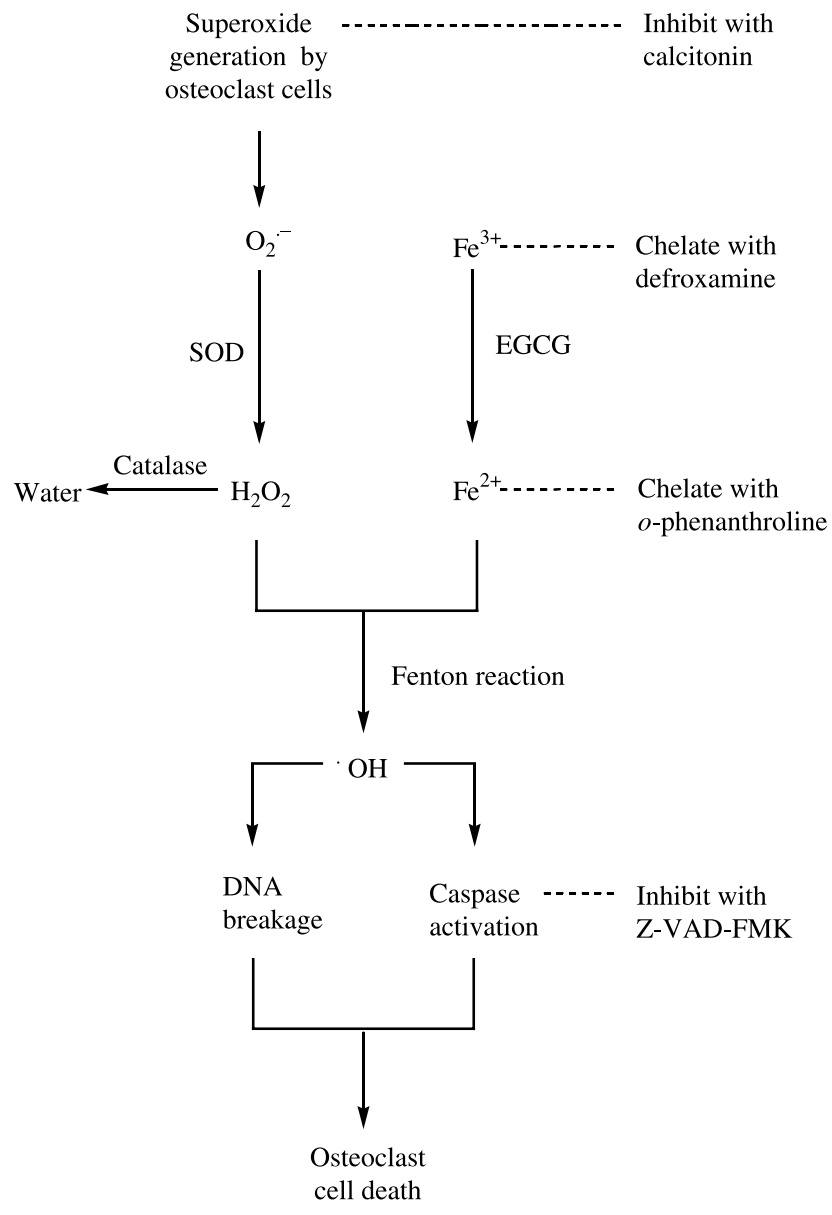

Fig. 4. Proposed mechanism of epigallocatechin gallate (EGCG)mediated cell death in osteoclasts $\left(\right.$ adapted $\left.^{29}\right)$. EGCG promotes the reduction of $\mathrm{Fe}^{3+}$ to $\mathrm{Fe}^{2+}$. $\mathrm{Fe}^{2+}$ combines with $\mathrm{H}_{2} \mathrm{O}_{2}$ (converted from superoxide by superoxide dismutase (SOD)) in the Fenton reaction. Resultant hydroxyl radicals then cause DNA breakage and activation of caspase, both causing the death of osteoclast cells. Z-VAD-FMK, benzyloxycarbonyl-Val-Ala-Asp (OMe) fluoromethylketone.

quercetin $(10 \mathrm{~nm})$ was also shown to significantly reduce bone resorption. Wattel et ll $^{34}$ also showed quercetin to be a potent inhibitor of osteoclastic activity in cells prepared from rabbit bone (50\% inhibitory concentration $1.6 \mu \mathrm{M})$. Upon further analysis using purified cells, it was found that the flavonols induced osteoclastic apoptosis in a dosedependent manner. However, Notoya et al. ${ }^{35}$ reported that quercetin also inhibited the proliferation, differentiation and mineralisation of rat calvarial osteoblast-like cells in vitro. It would appear that further in vivo research is therefore required to better determine the role(s) of quercetin and its metabolites in human bone health.

The addition of rutin (at $0.25 \%$ ) to the diet of rats for $90 \mathrm{~d}$ was shown to prevent femoral trabecular bone loss following ovariectomy ${ }^{36}$. Furthermore, urinary excretion of deoxypyridinoline (an index of bone resorption) and $\mathrm{Ca}$ were increased in ovariectomised rats compared with rutinfed and control rats, whilst plasma levels of osteocalcin were increased in rutin-fed rats compared with control rats, suggesting that osteoblastic activity was stimulated by rutin.
Flavonoids: tea polyphenols and direct antioxidant activity. Tea polyphenols may also promote bone health through direct antioxidant action. For example, a mixture of polyphenols (mainly comprising a variety of catechins) extracted from green tea was shown to minimise significantly reductions in the viability of osteoblasts (isolated from neonatal Sprague-Dawley rat calvariae) in vitro as a result of oxidative stress ${ }^{37}$. Addition of $\mathrm{H}_{2} \mathrm{O}_{2}$ $(100 \mathrm{mmol} / \mathrm{l})$ to cells for $24 \mathrm{~h}$ resulted in a reduction in viability of approximately $85 \%$ assessed using flow cytometry analysis and an approximate $90 \%$ reduction assessed using the 3-(4,5-dimethylthiazol-2-yl)-2,5-diphenyltetrazolium bromide assay. However, pre-treatment of cells with a green tea polyphenol mixture $(200 \mu \mathrm{g} / \mathrm{ml})$ for $1 \mathrm{~h}$ at $37^{\circ} \mathrm{C}$ resulted in reductions in viability of approximately 25 and $40 \%$ as assessed by flow cytometry analysis and 3-(4,5-dimethylthiazol-2-yl)-2,5-diphenyltetrazolium bromide respectively. Park et al. ${ }^{37}$ also repeated the experiment using a xanthine oxidase-xanthine system as a free radical generator. Using enzyme (40 U/l) plus $250 \mu \mathrm{M}$ of substrate gave reductions in osteoblast viability of approximately 50 and $55 \%$ as assessed by flow cytometry analysis and 3-(4,5-dimethylthiazol-2-yl)-2,5-diphenyltetrazolium bromide respectively, compared with equivalent reductions of approximately 20 and $5 \%$ observed in green tea polyphenol-treated cells.

In reviewing the potential of tea to benefit $\mathrm{BMD}, \mathrm{Wu}$ et $a l .^{12}$ also noted that various studies show that flavonoids within tea may have the potential to alter mineral metabolism. Such behaviour may be direct or indirect in nature. Which of the mechanisms have significant effects in vivo remains to be established. It is also important to note that, as $\mathrm{Wu}$ et al. ${ }^{12}$ have suggested, some or all of these mechanisms might work independently or in synergy.

\section{Caffeine and bone health}

Besides being flavonoid-rich, tea is also mildly caffeinated (Table 2). Several epidemiological studies have shown a correlation between consumption of high-caffeine beverages and low BMD (see below). Therefore tea may represent an interesting paradox, in that it is a caffeinated beverage that appears to benefit bone health. Research into the mechanisms by which caffeine might affect BMD has yielded inconclusive results, so any potential negative effects of caffeine upon bone health remain highly controversial.

Epidemiological studies. Several epidemiological studies show caffeine consumption as a potential risk factor for low BMD and fracture. Yano et al. ${ }^{38}$ found that $\mathrm{Ca}$, milk, vitamin $\mathrm{C}$ and vitamin $\mathrm{D}$ intake were positively associated with bone mineral content after adjustment for biometric confounding factors, and the use of thiazide (a diuretic used to treat hypertension), history of non-violent fracture and strenuous exercise (males) and use of oestrogen (females) in a cohort of 2120 elderly residents of the USA of Japanese origin. The strength of the association was sex- and sitedependent. However, caffeine consumption was associated with a low bone mineral content at the distal radius and ulna regions in women. In the Framingham study ${ }^{39}$, a cohort of 
3170 men and women from the USA were examined every 2 years over a 12-year period, with relationships being adjusted for confounding factors (such as smoking, alcohol consumption, use of oestrogen and biometric data) but not others (such as $\mathrm{Ca}$ intake, exercise and use of medication promoting bone loss). A significant increased relative risk of hip fracture $(1.53 \%)$ over the 2-year period following examination was found for those with caffeine consumption in excess of the equivalent of two cups of coffee per d. Furthermore, it was found that those who changed from a high to low caffeine consumption reduced their relative risk of hip fracture.

Along with mechanistic data (see section on 'Putative mechanisms for the effects of caffeine upon bone mineral density'), such studies have combined to form the traditional assertion that to ensure good bone health, caffeine consumption should be limited. More recent studies, however, have brought the relevance of caffeine consumption to bone health into question (see Table 4). For example, Massey $^{40}$ and Nawrot et $a .^{41}$ point out that caffeine consumption is often associated with confounding factors such as an increased level of smoking, age, low socioeconomic status and a decreased $\mathrm{Ca}$ intake through the displacement of milk as a beverage. Several studies have found that after adjustment for such factors, relationships between caffeine consumption and low BMD become insignificant $^{42-44}$.

Where relationships between caffeine consumption and bone health persist, the effects of caffeine may be mediated by various factors including age ${ }^{45}$, genotype ${ }^{46}$ and $\mathrm{Ca}$ intake $^{47-49}$. Furthermore, despite $\mathrm{Ca}$ being the foremost mineral in bone, several studies have shown little or no association between $\mathrm{Ca}$ intake and BMD in the elderly ${ }^{50-52}$. Yano et al. $^{38}$ also found that nutrients had a minimal effect upon bone status in the elderly compared with known confounding factors. However, other studies have shown relatively high $\mathrm{Ca}$ intake in early life to be related to high BMD and lower risk of fracture in later life ${ }^{6,53}$.

Yano et al. ${ }^{38}$ also suggest that lifetime dietary habits may be more important for attaining a high peak bone mass than current dietary habits in the elderly. As many diet-BMD studies focus upon elderly cohorts, it is important to factor such information into study designs.

Putative mechanisms for the effects of caffeine upon bone mineral density. Several mechanisms for the effects of caffeine upon BMD have been suggested, including the alteration of the absorption efficiency of dietary Ca in vivo ${ }^{54}$ and the alteration of sex steroid levels in vivo ${ }^{55}$. However, a further suggestion that has received considerable attention is based on the calciuretic effect of caffeine. For example, caffeine consumption was shown to increase the urinary excretion of $\mathrm{Ca}$ significantly in 168 premenopausal women to such an extent that a $50 \%$ increase over the group mean was predicted to produce a shift in $\mathrm{Ca}$ balance of $-0.006 \mathrm{~g} / \mathrm{d}^{56}$. Yeh \& Aloia ${ }^{57}$ also found that increased dietary caffeine significantly promoted urinary $\mathrm{Ca}$ loss in both old and young rats (although intestinal absorption of $\mathrm{Ca}$ was increased in the young rats to compensate).

The relevance of the calciuretic effect to $\mathrm{Ca}$ balance is, however, questionable. For example, Chen \& Whitford ${ }^{58}$ observed that whilst urinary $\mathrm{Ca}$ excretion was directly proportional (and faecal fluoride excretion was indirectly proportional) to caffeine intake in rats (fed over 6 weeks), the metabolic balance of fluoride and $\mathrm{Ca}$ were not significantly affected and could not be related to either an observed reduction in mineral content of the tibia or to a reduced ash content of the femur epiphysis in the group with the highest caffeine consumption. It was therefore concluded that in rats even high concentrations of caffeine had no measurable effect upon the metabolic balance or tissue concentration of fluoride, Ca or P. Similarly, in a study of the effects of carbonated beverages upon urinary $\mathrm{Ca}$ in women aged 20-40 years ${ }^{56}$, of several beverages tested only caffeine-containing beverages significantly increased urinary excretion of $\mathrm{Ca}$. However, the increase in $\mathrm{Ca}$ excretion over the $5 \mathrm{~h}$ post-ingestion period measured was relatively small (4-14 mg). Furthermore, the authors noted that the calciuretic effect of caffeine was biphasic (i.e. calciuria was reduced later in the day, compensating for overall losses), leading Heaney \& Rafferty ${ }^{56}$ to conclude that the effects of carbonated beverages upon $\mathrm{Ca}$ balance were minor, and that epidemiological associations between consumption of carbonated beverages and low BMD were more likely to arise from the displacement of milk from the diet.

Other researchers have also observed the absence of a significant calciuretic effect when performing feeding studies with caffeine-containing beverages. For example, Sakamoto et ll $^{59}$ showed that the only difference between rats fed on a diet containing instant coffee (at 0.62 and $1.36 \%$, equivalent to a human consumption of nine and twenty cups/d respectively) or a coffee-free diet was that urinary $\mathrm{P}$ excretion was increased in the former group (probably due to the $\mathrm{P}$ content of coffee). They showed that caffeine consumption did not lead to bone resorption, did not affect osteoclast levels or the production of boneresorping cytokines and did not affect levels of urinary deoxypyridinoline or serum osteocalcin, both of which are indicators of bone resorption and formation.

It is also possible that caffeine-containing beverages may contain other components that affect bone health. In a study by García-Contreras et al. ${ }^{60}$ ovariectomised rats given colabased drinks for 2 months had significantly lower femoral $\mathrm{BMD}$ and $\mathrm{Ca}$ concentration (although LS and pelvic BMD was unaffected by cola-based drink consumption) than rats given drinking water. Paired eating experiments showed that the effect was independent of food intake. Whilst citing the caffeine content of beverages as one of several potential contributors, García-Contreras et al. ${ }^{60}$ stated that the most likely cause of the observed effects may have been due to the high phosphoric acid content of cola-based drinks, as high phosphate consumption inhibits the absorption of $\mathrm{Ca}$ from the intestine, and renal tubular reabsorption.

The significance of caffeine to bone mineral density: conclusions. For a more detailed discussion of the effects of caffeine upon BMD, the reader is directed to a comprehensive review by Heaney ${ }^{61}$. As Massey ${ }^{62}$, Heaney ${ }^{61}$ and Nawrot et $a .^{41}$ point out, the association between caffeine consumption and other confounding factors (smoking, age, Ca intake) makes it difficult to assess the significance of any impact of 
Table 4. Summary of three selected groups of studies challenging current views on caffeine and bone mineral density (BMD)

\begin{tabular}{|c|c|}
\hline Reference & Population \\
\hline $\begin{array}{l}\text { Conlisk \& Galuska } \\
\qquad(2000)^{44}\end{array}$ & $\begin{array}{l}\text { Caucasian young adult } \\
\text { women }(n 177)\end{array}$ \\
\hline $\begin{array}{l}\text { Johansson et al. } \\
\left(_{(1992)^{42}}\right.\end{array}$ & $\begin{array}{l}\text { Swedish men and } \\
\text { women aged } \\
70 \text { years }(n 619)\end{array}$ \\
\hline $\begin{array}{l}\text { Lloyd et al. } \\
\qquad(1997)^{43}\end{array}$ & $\begin{array}{l}\text { Caucasian postmenopausal } \\
\text { women aged } 55-70 \text { years } \\
\text { ( } n \text { 138). Participants had } \\
\text { never undergone HRT or } \\
\text { had only used HRT for less } \\
\text { than } 1 \text { year }\end{array}$ \\
\hline $\begin{array}{l}\text { Cooper et al. } \\
(1992)^{45}\end{array}$ & $\begin{array}{l}\text { Caucasian women, aged } \\
40-80 \text { years }(n 290)\end{array}$ \\
\hline $\begin{array}{l}\text { Rapuri et al. } \\
\qquad(2001)^{46}\end{array}$ & $\begin{array}{l}\text { Postmenopausal women } \\
\text { ( } 489 \text { in cross-sectional } \\
\text { baseline study, ninety-six } \\
\text { in longitudinal study) } \\
\text { aged } 65-77 \text { years }\end{array}$ \\
\hline
\end{tabular}

$\underset{(1987)^{47}}{\text { Bergman }}$ et al. $\quad \begin{gathered}\text { Women aged } 31-78 \text { years } \\ (n 37)\end{gathered}$

Harris \& DawsonHughes $(1994)^{48}$

Ilich et al. (2002) ${ }^{49}$
Caucasian postmenopausal women $(n 136)$
Postmenopausal women (n 205)

Men over the age of

50 years $(n 523)$
Caffeine intake was associated with lower BMD. After correction for confounders (including smoking, alcohol and $\mathrm{Ca}$ intake), caffeine consumption (over the range consumed) was not a significant predictor of BMD

Coffee drinking was associated with lower BMD, deteriorated dental state, high tobacco use and low socio-economic status. After correction for confounders the correlation became insignificant. Whilst high BMD was associated with a high socio-economic status, coffee drinking was an indicator of both low socioeconomic status and tobacco use

No association between caffeine intake and bone density was found. Current and previous smoking and alcohol consumption habits were included in the exclusion criteria, with all participants being non-smokers consuming one or less alcoholic drink per $\mathrm{d}$. No association between caffeine intake and either total bone density or femoral neck bone density was found, even for those in the lowest tertile of $\mathrm{Ca}$ intake

Caffeine consumption had no significant correlation with bone mineral at five out of six sites tested. High caffeine consumption was associated with a high BMD at the femoral shaft in women under 60 years, but a slightly lower BMD in those aged 60 years and above

After a 3-year follow-up (longitudinal study), BMD at the spine was lost at a higher rate in participants consuming more than $300 \mathrm{mg}$ caffeine/d, compared with those with a lower caffeine consumption. Within 'high' caffeine consumers, women of the $t t$ VDR genotype had significantly higher rates of spinal BMD loss than those of the TT genotype, yet the same relationship was not observed within the 'low' caffeine consumption group. The presence of the $t t$ genotype may indicate an increased susceptibility to the effects of caffeine within postmenopausal elderly women. Massey $(2001)^{62}$ has pointed out that only five of the thirty-three women in the 'high' caffeine consumption group had the tt genotype, suggesting that a susceptibility to caffeine within a small segment of the population would be difficult to detect in studies where genotype is not considered

Various indicators of bone metabolism, serum mineral concentrations and urinary mineral excretion were measured during a $3 \mathrm{~d}$ period where caffeine was or was not permitted. All women reported habitual daily caffeine intake of $\geq 200 \mathrm{mg}$. Participants with $\mathrm{Ca}$ intakes below $600 \mathrm{mg} / \mathrm{d}(n 11)$ had significantly reduced levels of serum $\mathrm{Ca}$ and ultrafiltrable $\mathrm{Ca}$, plus increased bone alkaline phosphatase during caffeine consumption. However, participants with $\mathrm{Ca}$ intakes above $600 \mathrm{mg} / \mathrm{d}$ ( $n$ 26) did not exhibit similar changes

Mean caffeine and Ca intakes were 349 (sD/308) and 766 (sD/202) mg/d respectively. Rates of bone change did not differ significantly with caffeine consumption in women with a Ca intake above the median. However, higher caffeine intake was associated with greater bone loss in women with lower $\mathrm{Ca}$ intakes

A daily intake of $200-300 \mathrm{mg}$ caffeine was associated with low BMD at the majority of sites tested. In participants with a $\mathrm{Ca}$ intake below the median of $750 \mathrm{mg} / \mathrm{d}$, BMD values at the femoral neck and trochanter were significantly lower in caffeine consumers compared with non-consumers. However, there was no significant difference between BMD values for caffeine nonconsumers in the lower $\mathrm{Ca}$ intake group, and values for caffeine consumers and non-consumers in the higher $\mathrm{Ca}$ intake group. Therefore, caffeine appeared to have less influence upon bone in those with higher $\mathrm{Ca}$ intakes

Whilst milk consumption was positively associated with BMD, the relationship was not always significant. Current $\mathrm{Ca}$ intake had no relationship to BMD of the hip. $\mathrm{BMD}$ and caffeine consumption were not associated 
Table 4. Continued

\begin{tabular}{|c|c|c|c|}
\hline Reference & Population & Results & Comment \\
\hline Rico et al. $(2002)^{52}$ & $\begin{array}{l}\text { Postmenopausal } \\
\quad \text { women }(n 93)\end{array}$ & $\begin{array}{l}\text { Vitamin D (not caffeine) was the only dietary component } \\
\text { significantly related to BMD }\end{array}$ & $\ddagger$ \\
\hline $\begin{array}{l}\text { Hannan et al. } \\
\qquad(2000)^{51}\end{array}$ & $\begin{array}{l}\text { Elderly men and } \\
\text { women }(n 800)\end{array}$ & $\begin{array}{l}\text { Whilst risk factors differed between the sexes, caffeine and } \\
\text { Ca intake did not significantly affect bone mineral } \\
\text { density measured at six separate sites at 4-year } \\
\text { intervals }\end{array}$ & $\ddagger$ \\
\hline $\begin{array}{l}\text { Johnell et al. } \\
\quad(1995)^{6}\end{array}$ & $\begin{array}{l}\text { Women ( } n \text { 5618; } 2086 \\
\text { hip fracture cases, } 3532 \\
\text { controls) aged over } 50 \\
\text { years from fourteen } \\
\text { centres in six countries } \\
\text { across southern Europe; } \\
\text { MEDOS }\end{array}$ & $\begin{array}{l}\text { Higher intake of Ca from the consumption of milk during } \\
\text { childhood, adulthood and the recent past was } \\
\text { significantly related to lower risk of hip fracture. The } \\
\text { relationship was not linear, with increased risks being } \\
\text { limited to the } 10 \% \text { with the lowest level of consumption }\end{array}$ & $\ddagger$ \\
\hline New et al. $(1997)^{53}$ & $\begin{array}{l}\text { Premenopausal } \\
\quad \text { women }(n \text { 994) }\end{array}$ & $\begin{array}{l}\text { Whilst current Ca intake was not associated with BMD, } \\
\text { BMD was significantly related to reported milk intake in } \\
\text { earlier life }\end{array}$ & $\ddagger$ \\
\hline
\end{tabular}

HRT, hormone replacement therapy; VDR, vitamin D receptor; MEDOS, Mediterranean Osteoporosis Study.

* After adjustment for confounding factors, relationships between caffeine consumption and low BMD often become insignificant.

† Where relationships between caffeine consumption and bone health persist, the effects of caffeine may be mediated by various factors.

$\ddagger$ It is likely that lifetime dietary habits have more effect upon BMD than current nutrient consumption.

caffeine consumption and bone status. Yet, several conclusions can be drawn. First, caffeine has various metabolic effects in vivo which can be measured, although the review by Heaney ${ }^{61}$ suggested that the most likely prominent mechanism of effect is a moderation in $\mathrm{Ca}$ absorption efficiency rather than calciuresis. Heaney ${ }^{61}$ also noted that whilst decreases in BMD are the most studied factor of skeletal fragility, fatigue and falls are also highly important and as yet no studies have considered whether caffeine has any effect upon repair of damaged bones. Nevertheless, when the evidence is considered, it can be concluded that the effect of caffeine upon BMD is likely to be mild for the majority of the population. Second, certain factors may increase the susceptibility of an individual to the effects of caffeine. Adequate Ca intake is one such factor; an opinion supported by Nawrot et al. ${ }^{41}$, who state that current evidence indicates that individuals consuming a minimum $800 \mathrm{mg}$ Ca daily would not be significantly affected by daily caffeine intakes of below $400 \mathrm{mg}$. Considering the low caffeine content (per serving) of tea (Table 2), an individual with adequate $\mathrm{Ca}$ intake would have to habitually drink somewhere between or beyond eight to thirteen cups/d in order to be at any risk. Age is another important factor. Massey ${ }^{62}$ stated that current evidence would suggest the elderly are less able than their younger counterparts to adapt their $\mathrm{Ca}$ absorption levels to counteract caffeine-induced urinary loss. The effects of caffeine in vivo are also likely to be complicated by other factors such as sex (women appear more susceptible than men), genetic predisposition, current physical status, diet and the amount ingested.

Table 5 summarises the tea components that may affect bone health.

\section{Fruit, vegetables and bone health}

The consumption of fruit and vegetables has been associated (for example, Steinmetz \& Potter ${ }^{63}$ ) with reduced risk of various oxidative stress-related diseases such as cancer and heart disease. Such information led the WHO in 1990 to set a daily target for consumption of at least $400 \mathrm{~g}$ fruit and vegetables (including $30 \mathrm{~g}$ nuts, pulses and seeds), which has been interpreted by the regulatory authorities and health groups of many countries as the 'five portions of fruit and vegetables daily' advice. However, fruit and vegetable consumption has traditionally been associated with many other aspects of health, including that of bone formation and maintenance.

\section{Epidemiological studies}

Several studies have noted favourable relationships between $\mathrm{BMD}$ and the consumption of fruit and vegetables across a wide range of age groups.

For example, a 'high' consumption of fruit and vegetables (three or more portions per d) was significantly related to higher bone area of the non-dominant wrist (8.3\%) and the whole body (6\%) compared with a 'low' consumption (less than three portions) in a group of fifty-six Caucasian earlypubertal girls ${ }^{64}$. Furthermore, those girls studied with higher fruit and vegetable consumption also had lower urinary excretion of $\mathrm{Ca}$ and parathyroid hormone. Similarly, the Saskatchewan Bone Mineral Accrual Study ${ }^{65}$ showed that consumption of fruit and vegetables of less than five portions daily was associated with lower accumulation of bone mineral in adolescent girls, but not boys. Differences in $\mathrm{Ca}$ absorption efficiency as well as intake were suggested as possible explanations for sex-based differences in accumulation of bone mineral. Similar sex-based disparities were reported by McGartland et al. ${ }^{66}$, who observed (before adjustment) that heel BMD was significantly higher in 12-year-old ( $n$ 378) and 15-year-old ( $n$ 369) girls with a higher consumption of fruit compared with girls with moderate and lower intakes respectively. Whilst adjustment for various potential confounding factors such as body weight, height, smoking status and physical activity removed the significant association between heel BMD 
Table 5. Tea components that may affect bone health, supporting epidemiological studies through in vitro and in vivo experimentation

\begin{tabular}{|c|c|}
\hline Component & Effect \\
\hline Catechins & There is in vitro and in vivo evidence for catechins having a positive effect on bone health \\
\hline Flavonoids & Flavonoids in tea other than catechins may positively affect bone health through a number of different mechanisms \\
\hline Fluoride & The fluoride content of green and black teas may have a positive effect on bone health \\
\hline Fluoride & Excessive consumption of brick tea (consumed in Tibet) can lead to fluorosis because of high fluoride levels \\
\hline
\end{tabular}

and fruit intake in 15-year-old girls, the same relationship for 12-year-old girls was reinforced. No associations between fruit intake and BMD were found at the forearm in the girls, or at either site in boys aged 12 years $(n 324)$ and 15 years $(n 274)$.

In a group of 994 premenopausal women from Scotland, BMD was found to be significantly lower at the LS, FN, femoral trochanter and the femoral Ward's sites in those reporting a low intake of fruit in early adulthood compared with medium or high intakes at the same ages ${ }^{53}$. After adjustment for various confounders, the relationship remained significant for the LS and femoral trochanter sites. Chen et al. ${ }^{67}$ report that bone health was related to fruit (but not vegetable) intake in a group of 668 Chinese women who had experienced early menopause. High BMD and BMC of the whole body, LS and left hip was associated with high levels of fruit consumption, after adjustment for age, years since menopause and BMI, remaining significant after adjustment for physical activity and intake of $\mathrm{Ca}, \mathrm{P}$ and protein.

In studying the dietary habits of the elderly, Tucker et al. ${ }^{68}$ found that BMD was highest in men with a greater consumption of fruit, vegetable and cereal and lowest in men with a greater consumption of high-sugar sweets compared with most other consumption groups. Women with high consumption of high-sugar sweets also had the lowest BMD compared with other groups; however, both those with a high fruit, vegetable and cereal consumption and those with high alcohol consumption were shown to have high BMD values. Whilst alcoholism is traditionally associated with poor bone health, any beneficial association between BMD and alcohol consumption might be explained in part by the flavonoid and phyto-oestrogen contents of wine and beer respectively. Fruit and vegetable intake was again significantly associated with BMD at three out of four sites tested in men and two out of four sites tested in women within the same cohort in an earlier study ${ }^{69}$. Furthermore, after a 4-year interval, high intakes of fruit and vegetables in the baseline diet were associated with significantly less bone loss at one site in men (although there was no similar association for women). However, $\mathrm{K}$ intake had a more pronounced relationship with BMD at baseline, with high $\mathrm{K}$ and $\mathrm{Mg}$ intakes being associated with significantly less bone loss at two sites in men.

Not all studies show such clear associations. In a study of 944 subjects aged $67-79$ years (470 male, 474 female) fruit and vegetable consumption was not linked to rate of total hip BMD $\operatorname{loss}^{70}$. However, vitamin $\mathrm{C}$ intake was significantly linked to BMD conservation in women. Those in the highest consumption tertile $(99-363 \mathrm{mg} / \mathrm{d})$ lost BMD at a rate of $0.30 \%$ annually, compared with $0.65 \%$ annually for those in the lowest consumption tertile
(7-57 mg/d); almost twice the rate of bone mineral loss. Those in the middle consumption tertile $(58-98 \mathrm{mg} / \mathrm{d})$ lost bone mineral at a rate of $0.31 \%$ annually, suggesting that even small increases in vitamin $\mathrm{C}$ intake might benefit bone health.

Several other studies have linked the consumption of nutrients present within fruit and vegetables to bone health. For example, in studying a group of 891 women (aged 4555 years at baseline) Macdonald et al. ${ }^{71}$ found that $\mathrm{Ca}$, vitamin $\mathrm{C}, \mathrm{Mg}$ and $\mathrm{K}$ were associated with high $\mathrm{FN} \mathrm{BMD}$ in women who were still menstruating at follow-up (5-7 years after baseline). Furthermore, $\mathrm{Ca}$, vitamin $\mathrm{C}$ and $\mathrm{Mg}$ were associated with FN bone change in the 146-strong subgroup. In the study by New et al..$^{53}$ dietary intakes of vitamin $\mathrm{C}, \mathrm{Mg}, \mathrm{K}, \mathrm{Zn}$ and fibre were positively related to BMD. After adjustment for confounders, $\mathrm{Mg}$ and vitamin $\mathrm{C}$ intake were significantly associated with BMD at the LS, whilst K intake was associated with BMD at the LS, FN, femoral trochanter and femoral Ward's sites. In a later study, New et al $^{72}$ also showed that nutrients from fruit and vegetables (including $\mathrm{K}, \beta$-carotene, vitamin $\mathrm{C}$ and $\mathrm{Mg}$ ) were positively and significantly associated with bone health in a group of sixty-two healthy pre-, peri- and postmenopausal women, with FN BMD being significantly higher in those reporting a higher (one to four portions; $\geq 5 \mathrm{~d} /$ week) compared with medium or lower (one to four portions, $\leq 2 \mathrm{~d}$ per week) fruit consumption during childhood.

\section{Putative mechanisms of the effects of fruit and vegetables upon bone mineral density}

It has been suggested that bone demineralisation may be in part mediated by diets high in acid-forming components (amino acids, $\mathrm{P}$, chlorine) and low in base-forming components $(\mathrm{K}, \mathrm{Ca}, \mathrm{Mg} \text {, vitamin } \mathrm{C})^{73}$, with the skeleton acting as a buffer, thus playing a vital role in $\mathrm{pH}$ balance. It is therefore possible that the protective effects of fruit and vegetables may be due to their content of base-forming components. A great deal of evidence surrounds and supports this theory (which is beyond the scope of the present review), and for a more detailed synopsis the reader is directed to a comprehensive review by $\mathrm{New}^{74}$.

It is entirely possible, however, that the protective effect of fruit and vegetables upon bone health is not exclusively dependent upon the ability of fruit and vegetable components to neutralise acid components of the diet, a prospect highlighted by the work of Mühlbauer et al. ${ }^{75}$. Here, the bone-related effects of adding various plant foods to the diets of rats were observed. Rats were pre-labelled with $\left[{ }^{3} \mathrm{H}\right]$ tetracycline through a series of subcutaneous injections (during the first 6 weeks of life). The urinary excretion of ${ }^{3} \mathrm{H}$ (determined by liquid scintillation counting) 
was used as an indication of bone resorption. Rats were fed a diet either with or without animal protein (casein), with both diets being similar in terms of protein, $\mathrm{Ca}$ and phosphate content. Rats fed a vegetarian diet had urine that was high in $\mathrm{pH}$, low in ammonium and had negative titratable acid. Upon conversion to the casein diet, urine became low in $\mathrm{pH}$, comparatively high in ammonium and had higher titratable acid content. Addition of onion (7\%) to the diet of caseinfed rats had the effect of mildly raising urinary $\mathrm{pH}$ and slightly lowering ammonium and titratable acid content. However, bone resorption was reduced by 18 (SE/2)\%.

Taken alone, these results could support the acid-base theory. However, Mühlbauer et al. $^{75}$ also report that bone resorption was lowered (13 (SE/2) \%) by the addition of onion to rats fed on the vegetarian diet. The more pronounced effect of onion upon rats fed the casein diet might have been mediated by an increase in base-forming components. However, supplementation of casein diets with potassium citrate (to buffer $\mathrm{pH}$ to levels similar to the vegetarian diet) slightly improved the effects of either onion or a mixture of fourteen vegetables, salads and herbs (previously observed to inhibit bone resorption in rats) ${ }^{76}$ yet had no effect on bone resorption in the absence of these vegetables. The authors concluded that the base excess of the vegetarian diet was unlikely to mediate differences in response of the two diet types to the addition of onion or vegetable mix. Furthermore, the $\mathrm{K}$ content of test samples did not correlate with levels of bone resorption. In a follow-up study ${ }^{77}$, several other test samples including fennel, celeriac, prunes, oranges, French beans, farmed and wild mushrooms and red wine residue were also shown to significantly reduce bone resorption in rats. However, perhaps more importantly, seventeen other plant foods tested had no significant effect. In discussing all three studies, Mühlbauer et al. ${ }^{77}$ noted inconsistencies between these results and the acid-base balance theory. Mühlbauer et al. ${ }^{77}$ therefore suggest that the benefit accrued by prevention of bone resorption shown by some plant foods may be derived from 'pharmacologically active compounds'.

\section{Role for polyphenols?}

Polyphenols, also present in significant concentrations within fruits and vegetables, may be candidates for one such group of compounds, with several having been shown to affect bone metabolism (for example, onions are an excellent source of various quercetin conjugates, such as rutin; see 'Effects of flavonoids on bone health' section). For instance, the daily consumption of $100 \mathrm{~g}$ dried plums (rich in anthocyanin flavonoids) in postmenopausal women was shown to increase significantly levels of insulin-like growth factor-1 and bone-specific alkaline phosphatase in serum after 3 months, indicating increased bone formation ${ }^{78}$. Chiba et al. $^{79}$ found that femoral bone loss caused by ovariectomy in 8-week-old female mice could be prevented by treatment with either hesperidin (a flavonoid common to citrus fruit) or $\alpha$-glucosylhesperidin. Treatment of bone samples with tartrate-resistant acid phosphatase showed that trabecular bone resorption was prevented through a reduction in the number of osteoclast cells. Hesperidin treatment also increased femoral $\mathrm{Ca}$ concentration to slightly above that for mice in the control group (sham-operated), whereas femoral $\mathrm{Ca}$ concentration was lower 4 weeks after ovariectomy in mice not treated with hesperidin.

Phyto-oestrogens and bone mineral density. A large amount of work concerning the effects of isoflavones (Fig. 3) upon BMD has also been performed. In vitro, various isoflavones have been shown to inhibit bone resorption in bone culture through promoting the proliferation and activity of osteoblast cells and suppressing the proliferation and activity of osteoclast cells ${ }^{80}$. The structural and possible in vivo functional similarities between isoflavones and oestrogens have also highlighted the possibility that supplementation may benefit postmenopausal women, in terms of general as well as bone-specific health. The potentially harmful side effects of HRT such as swelling and bleeding of the uterus, CVD, gallbladder disease and increased risk of various cancers ${ }^{81}$ mean that reliable dietary supplementation would be of considerable benefit. Therefore, much of the in vivo work in this field is focused upon ovariectomised rats and postmenopausal women. It has to be noted that in this area in particular, promising in vitro studies have proved difficult to confirm in vivo in human studies.

Twice-weekly intramuscular injections with either coumestrol $(1.5 \mu \mathrm{M})$ or zearalanol $(3.1 \mathrm{mmol})$ inhibited bone loss in ovariectomised rats over a 6 -week period ${ }^{82}$. However, incorporating a mixture of isoflavones extracted from clover (biochanin A, formononetin and genistein) into the diet of rats $(131.25 \mathrm{mg} /$ week) did not reduce bone loss compared with control rats following ovariectomy. In a similar study, Fanti et al. $^{83}$ showed that daily subcutaneous injections of $5 \mathrm{mg}$ genistein/ $\mathrm{kg}$ body weight inhibited reductions in BMD by over $50 \%$ (compared with control) $21 \mathrm{~d}$ after ovariectomy. Increasing the dose to $25 \mathrm{mg} / \mathrm{kg}$ body weight did not improve benefit, whilst doses of $1 \mathrm{mg} / \mathrm{kg}$ body weight had no effect upon bone loss. Though numbers of osteoblast cells were higher in ovariectomised compared with sham-operated animals, within the ovariectomised group osteoblast levels tended to be higher in rats treated with genistein. In a slightly longer study (16 weeks) Lee et al. ${ }^{84}$ showed that inclusion of soya isoflavone extract (comprising various aglycone and conjugate forms of genistein, daidzein and glycetein) in the diet of ovariectomised rats $(6.25 \mathrm{~g} / \mathrm{kg}$ diet, equivalent to about $10.67 \mathrm{mg} / \mathrm{d}$ ) significantly reduced losses in bone density and mineral content following ovariectomy. However, lower oral doses of isoflavones (approx 0.96 and $1.92 \mathrm{mg}$ daily) over a $40 \mathrm{~d}$ period did not protect rats from ovariectomy-induced bone loss ${ }^{85}$.

Certain studies have reported dietary exposure to phytooestrogens (as food or via supplementation) to benefit BMD in human subjects. For example, in a long-term, double-blind, randomised, placebo-controlled trial performed by Atkinson et $a l^{86}$, the effects of a daily isoflavone supplement (derived from red clover) containing biochanin A, daidzein, formononetin and genistein upon BMD and BMC of a group of women (aged 49-65 years) was assessed. In the 177 women that completed the trial, loss of BMC and BMD at the LS region was significantly lower in women receiving the isoflavone supplement compared with those receiving a placebo. Although urinary markers of bone resorption were not significantly different between groups, markers of bone 
formation in plasma (bone-specific alkaline phosphatase and $\mathrm{N}$-propeptide of collagen type I) were significantly higher in postmenopausal women receiving the supplement compared with placebo. A similar study by Chen et al. ${ }^{87}$ observed changes in BMD with 175 (a sub-section of the 203 initially selected) postmenopausal Asian women (aged 48-62 years) before and after 12 months' treatment with soya. All participants consumed $500 \mathrm{mg} \mathrm{Ca}, 3 \cdot 125 \mu \mathrm{g}$ (125 IU) vitamin D plus differing quantities of soya isoflavones (predominantly daidzein, genistein and glycetein) on a daily basis. Women who received a high dose of soya ( $80 \mathrm{mg}$ isoflavones) had significantly higher positive BMC change rate at total hip and trochanter compared with those receiving a medium dose (40 mg isoflavones) or a placebo. Furthermore, closer analysis showed that the significant benefit of soya isoflavone supplementation in the high-dose group originated from women with lower initial BMC. However, in a comparable study $^{88}$, after 12 months' treatment with either a daily soya protein supplement (containing daidzein, genistein and glycetein) or a placebo there were no significant differences in BMD, markers of bone formation, or plasma levels of $\mathrm{Ca}$ and $\mathrm{P}$ between treatment groups in a cohort of 175 women aged between $60-75$ years.

Another field of intense research concerns the use of the synthetic isoflavone ipriflavone. In a study of postmenopausal women (aged 50-60 years, 1-5 years after menopause) two groups (one observed at the distal radius the other at the LS) were given $\mathrm{Ca}(1 \mathrm{~g} / \mathrm{d})$ plus either ipriflavone $(600 \mathrm{mg} / \mathrm{d})$ or placebo for 2 years ${ }^{89}$. Whilst those receiving placebo experienced reduced $\mathrm{BMD}$ at both regions, those taking ipriflavone had increased BMD at the distal radius (seventy women) or no significant reduction in BMD at the LS (thirty women). In a similar study by Maugeri et al. ${ }^{90}$, eighty-four female patients over the age of 65 years with a history of osteoporosis and fracture were treated with ipriflavone or placebo as above for 2 years. Whilst those receiving placebo had decreased BMD at the distal radius (as well as increased pain and use of analgesics), those receiving ipriflavone had increased BMD, decreased pain and decreased requirement for analgesics. In both studies urinary excretion of hydroxyproline was significantly reduced, with all subjects tolerating ipriflavone well, leading to the suggestion that ipriflavone has considerable potential as a therapeutic agent.

The volume of data regarding the subject of phytooestrogens and bone health is considerable, and to attempt to tackle this field in its entirety is beyond the scope of the present review. For a more thorough account of the situation regarding phyto-oestrogens and bone health, the reader is directed to reviews by Yamaguchi ${ }^{91}$, Branca $^{81}$ and Setchell $\&$ Lydeking-Olsen ${ }^{80}$.

\section{Role for other compounds?}

Whilst much evidence supports the theory that polyphenols may benefit bone health, it should be pointed out that other fruit and vegetable components might also play a part. For example, in reviewing functional ingredients and $\mathrm{BMD}$, Brouns \& Vermeer $^{92}$ also suggest that vitamin $\mathrm{K}$ and non-digestible carbohydrates may have potential benefits to bone health. Carotenoids may also play a role.
For example, total and LS BMD was associated with high lycopene consumption in a cohort of sixty-eight men, and with high lycopene, lutein or zeaxanthin consumption in a cohort of 137 women, within which was also observed a correlation between high BMD and intake of $\beta$-carotene ${ }^{93}$. It is therefore suggested that the benefits of consuming fruit and vegetables with regard to BMD may be the result of several groups of components, with many different mechanisms of benefit, meaning that the scope for investigating the action of fruit and vegetable components upon bone metabolism may not yet be fully realised.

\section{Conclusions}

Bone health is the combination of genetics, diet (Fig. 5) and lifestyle. Whilst genetic inheritance is difficult to control (at present), improvements in diet and lifestyle can reduce the risk of poor bone health. It has been suggested that whilst low BMD is often a problem of old age, it is the dietary habits of a lifetime that have the biggest effect upon $\mathrm{BMD}^{38}$. Therefore, emphasis should be placed on building a high BMD (through increasing the intake of beneficial components) over the long term rather than correcting a low BMD during old age. Several conclusions can be drawn regarding tea, caffeine, fruit and vegetables and their relationship to bone health.

First, tea is a mildly caffeinated beverage containing high levels of polyphenols which appears to potentially benefit bone health. Whilst the exact mechanism of these benefits is

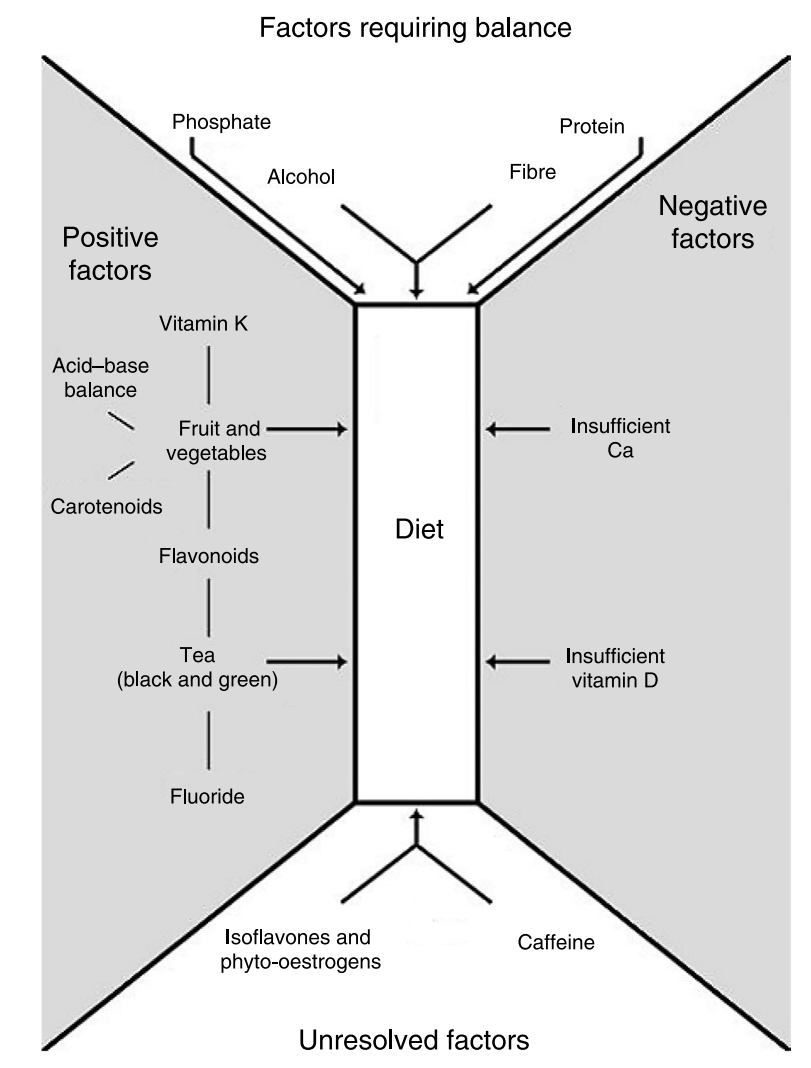

Fig. 5. Summary of some of the dietary factors that may affect bone health. 
unclear, both the F content and the polyphenolic content of tea may contribute to higher BMD.

Second, although consumption of caffeine may affect $\mathrm{Ca}$ balance through several potential mechanisms in vivo, the current evidence would suggest that this might only prove detrimental to BMD in those already susceptible to the effects of caffeine (i.e. inadequate $\mathrm{Ca}$ intake, a predisposition toward osteoporosis or old age). Whilst the consumption of caffeinated beverages may have been previously viewed as detrimental to BMD, caffeine may not be as deleterious to bone health as is currently indicated in much dietary advice to those at risk. Recommendations to at-risk groups to avoid certain plant-based foods containing caffeine may, therefore, actually cause harm in depriving consumers of dietary sources of bioactives with beneficial consequences for bone health.

Finally, high intakes of fruit and vegetables have also been associated with high BMD, and whilst this may partly stem from base-forming components $(\mathrm{K}, \mathrm{Ca}, \mathrm{Mg}$, vitamin $\mathrm{C})$, it is likely that polyphenols (including flavonoids and possibly phyto-oestrogens) may also contribute to bone health. Several other fruit and vegetable components such as lycopene, lutein and zeaxanthin, $\beta$-carotene, vitamin $\mathrm{K}$ and non-digestible carbohydrates have also been reported as potential bone enhancers, suggesting that fruit and vegetables may benefit bone health through a combination of different mechanisms.

In summation, there appears to be the possibility of significant positive effects on bone health from fruit, vegetables and tea. It is suggested that future research in the area focus upon the following:

(1) Human feeding studies. Epidemiology is a useful tool to highlight potential beneficial relationships between diet and bone health. However, more human in vivo studies (specifically double-blind, randomised, placebo-controlled trials) are required to confirm (or refute) the validity of such relationships (for foods and individual compounds). Development of reliable biomarkers of bone remodelling may help counter the large expense and timescales typical to the area.

(2) Detailed mechanistic exploration. Several mechanisms of benefit to bone health have been suggested for plantbased foods. However, the significance of these mechanisms to the in vivo situation remains to be confirmed. Such work must also consider the varied metabolism of bioactives. Where in vitro research is performed (for example, cell culture), it is vital that appropriate metabolites at appropriate concentrations to the target area be assessed, rather than compounds native to the food or extract under scrutiny.

(3) Investigate possibilities for synergy. Once mechanisms of benefit have been identified, it becomes possible to assess relationships between individual bioactives in either a given foodstuff or the diet in general. It may thus be possible to optimise any beneficial effects.

\section{Acknowledgements}

T. D. is in receipt of a BBSRC CASE studentship supported by the Tetley Group Ltd.

\section{References}

1. Kanis JA, Brazier JE, Stevenson M, Calvert NW \& Lloyd Jones M (2002) Treatment of Established Osteoporosis: a Systematic Review and Cost-Utility Analysis, Health Technology Assessment 6, no. 29. Southampton: National Coordinating Centre for Health Technology Assessment.

2. Torgerson DJ, Iglesias CP \& Reid DM (2001) The economics of fracture prevention. In The Effective Management of Osteoporosis, pp. 111-122 [DH Barlow, RM Francis and A Miles, editors]. London: Aesculapius Medical Press.

3. Heaney RP \& Recker RR (1982) Effects of nitrogen, phosphorus, and caffeine on calcium balance in women. $J$ Lab Clin Med 99, 46-55.

4. Ganong WF (1979) Review of Medical Physiology, 9th ed. Stamford, CT, USA: Appleton and Lange.

5. Smith R (1993) Bone mineral. In Human Nutrition and Dietetics, 9th ed., pp. 163-173 [JS Garrow and WPT James, editors]. Edinburgh: Churchill Livingston.

6. Johnell OJ, Gullberg B, Kanis JA et al. (1995) Risk factors for hip fracture in European women: The MEDOS study. $J$ Bone Miner Res 10, 1802-1815.

7. Weisburger JH (1997) Tea and health: a historical perspective. Cancer Lett 114, 315-317.

8. Hoover PA, Webber CE, Beaumont LF \& Blake JM (1996) Post-menopausal bone mineral density: relationship to calcium intake, calcium absorption, residual oestrogen, body composition, and physical activity. Can J Physiol Pharmacol 74, 911-917.

9. Hegarty VM, May HM \& Khaw K-T (2000) Tea drinking and bone mineral density in older women. Am J Clin Nutr 71, $1003-1007$.

10. Crawley H (1990) Food Portion Sizes, 2nd ed. London: Her Majesty's Stationery Office.

11. Paul AA \& Southgate DAT (1978) McCance, Widdowson's 'The Composition of Foods', 4th ed. London: Her Majesty's Stationery Office.

12. Wu C-H, Yang Y-C, Yao W-J, Lu F-H, Wu JS \& Chang C-J (2002) Epidemiological evidence of increased bone mineral density in habitual tea drinkers. Arch Intern Med 162, 1001-1006.

13. Muraki S, Yamamoto S, Ishibashi H, Horiuchi T, Hosoi T, Suzuki T, Orimo H \& Nakamura K (2003) Green tea drinking is associated with increased bone mineral density. $J$ Bone Miner Res 18, Suppl. 2, S241.

14. Vestergaard P, Herman AP, Gram J et al. (2001) Evaluation of methods for prediction of bone mineral density by clinical and biochemical variables in perimenopausal women. Maturitas 40, 211-220.

15. Chen Z, Pettinger MB, Ritenbaugh $\mathrm{C}$, LaCroix AZ, Robbins J, Caan BJ, Barad DH \& Hakim IA (2003) Habitual tea consumption and risk of osteoporosis: a prospective study in the women's health initiative observational cohort. Am $J$ Epidemiol 158, 772-781.

16. Chen Z, Pettinger MB, Hakim LA, LaCroix AZ, Robbins J, Caan BJ, Barad DH \& Ritenbaugh C (2002) Does tea drinking affect bone density and risk of fractures among US post-menopausal women with different states of hormone replacement therapy? Results from the observational study in the women's health initiative. J Bone Miner Res 17, SA278.

17. Grynpas MD, Chachra D \& Limeback H (2000) The action of fluoride on bone. In The Osteoporosis Primer, pp. 318-330 [JE Henderson and D Goltzman, editors]. Cambridge, UK: Cambridge University Press.

18. Whitford GM (1996) The Metabolism and Toxicity of Fluoride, 2nd ed. Basel and London: Karger. 
19. Fung KF, Zhang ZQ, Wong JWC \& Wong MH (1999) Fluoride contents in tea and soil from tea plantations and the release of fluoride into tea liquor during infusion. Environ Pollut 104, 197-205.

20. Duckworth SC \& Duckworth R (1978) The ingestion of fluoride in tea. Br Dent $J$ 145, 368-370.

21. Hallberg L, Sandström B \& Agget PJ (1993) Iron, zinc and other trace elements. In Human Nutrition and Dietetics, 9th ed., pp. 174-207 [JS Garrow and WPT James, editors]. Edinburgh: Churchill Livingston.

22. Cao J, Zhao Y, Liu J, Xirao R, Danzeng S, Daji D \& Yan Y (2003) Brick tea fluoride as a main source of adult fluorosis. Food Chem Toxicol 41, 535-542.

23. Zhang M, Shimmura T, Nishino H, Bi LF, Kajita E, Nagata M, Nagase H, Wang HB, Aratani T \& Kagamimori S (2003) Influence of fluoride concentration in drinking water and brick-tea water on bone mass in healthy Inner Mongolian young women. Bone 32, S186.

24. Cao J, Zhao Y \& Liu J (2001) Prevention of brick tea fluorosis in rats with low-fluoride brick tea on laboratory observation. Food Chem Toxicol 39, 615-619.

25. Whyte MP, Essmyer K, Gannon FH \& Reinus WR (2005) Skeletal fluorosis and instant tea. Am J Med 118, 78-82.

26. Dufresne CJ \& Farnworth ER (2001) A review of latest research findings on the health promotion properties of tea. $J$ Nutr Biochem 12, 404-421.

27. Delaissé J-M, Eeckhout Y \& Vaes G (1986) Inhibition of bone resorption in culture by $(+)$-catechin. Biochem Pharmacol 35, 3091-3094.

28. Park H, Ko S, Kim J \& Kim S (2003) Effects of green tea extracts and polyphenols on the proliferation and activity of bone cells. J Bone Miner Res 18, Suppl. 2, S342.

29. Nakagawa H, Wachi M, Woo J-T, Kato M, Kasai S, Takahashi F, Lee I-S \& Nagai K (2002) Fenton reaction is primarily involved in a mechanism of (-)-epigallocatechin3 -gallate to induce osteoclastic cell death. Biochem Biophys Res Comm 292, 94-101.

30. Choi E-M \& Hwang J-K (2003) Effects of (+)-catechin on the function of osteoblastic cells. Biol Pharm Bull 26, $523-526$.

31. Choi J-H, Rhee I-K, Park K-Y, Park K-Y, Kim J-K \& Rhee SJ (2003) Action of green tea catechin on bone metabolic disorder in chronic cadmium-poisoned rats. Life Sci 73, 1479-1489.

32. Takita H, Kikuchi M, Sato Y \& Kuboki Y (2002) Inhibition of BMP-induced ectopic bone formation by an antiangiogenic agent (epigallocatechin 3-gallate). Connect Tissue Res 43, 520-523.

33. Rassi CM, Lieberherr M, Chaumaz G, Pointillart A \& Cournot G (2005) Modulation of osteoclastogenesis in porcine bone marrow cultures by quercetin and rutin. Cell Tissue Res 319, 383-393.

34. Wattel A, Kamel S, Mentaverri R, Lorget F, Prouilet C, Petit J-P, Fardelonne P \& Brazier M (2003) Potent inhibitory effect of naturally occurring flavonoids quercetin and kaempferol on in vitro osteoclastic bone resorption. Biochem Pharmacol 65, 35-42.

35. Notoya M, Tsukamoto $\mathrm{Y}$, Nishimura H, Woo J-T, Nagai K, Lee I-S \& Hagiwara H (2004) Quercetin, a flavonoid, inhibits the proliferation, differentiation, and mineralization of osteoblasts in vitro. Eur J Pharmacol 485, 89-96.

36. Horcajada-Molteni M-N, Crespy V, Coxam V, Davicco M-J, Rémésy C \& Barlet J-P (2000) Rutin inhibits ovarectomyinduced osteopenia in rats. J Bone Miner Res 15, 2251-2258.

37. Park YH, Han D-W, Suh H, Ryu GH, Hyon S-H, Cho BK \& Park J-C (2003) Protective effects of green tea polyphenol against reactive oxygen species-induced oxidative stress in cultured rat calvarial osteoblast. Cell Biol Toxicol 19, 325-337.

38. Yano K, Heilbrun LK, Wasnich RD, Hankin JH \& Vogel JM (1985) The relationship between diet and bone mineral content of multiple skeletal sites in elderly JapaneseAmerican men and women living in Hawaii. Am J Clin Nutr 42, 877-888.

39. Kiel DP, Felson DT, Hannan MT, Anderson JJ \& Wilson PW (1990) Caffeine and the risk of hip fracture: the Framingham study. Am J Epidemiol 132, 675-684.

40. Massey LK (1991) Perspectives caffeine and bone: directions for research. J Bone Miner Res 6, 1149-1151.

41. Nawrot P, Jordan S, Eastwood J, Rotstein J, Hugenholtz A \& Feeley M (2003) Effects of caffeine on human health. Food Addit Contam 20, 1-30.

42. Johansson C, Mellström D, Lerner U \& Österberg T (1992) Coffee drinking: a minor risk factor for bone loss and fractures. Age Ageing 21, 20-26.

43. Lloyd T, Rollings N, Eggli DF, Kieselhorst K \& Chinchilli VM (1997) Dietary caffeine intake and bone status of postmenopausal women. Am J Clin Nutr 65, 1826-1830.

44. Conlisk AJ \& Galuska DA (2000) Is caffeine associated with bone mineral density in young adult women? Prev Med 31, $562-568$.

45. Cooper G, Atkinson EJ, Wahner HW, O'Fallon WM, Riggs BL, Judd HL \& Melton LJ (1992) Is caffeine consumption a risk factor for osteoporosis? J Bone Miner Res 7, 465-471.

46. Rapuri PB, Gallagher JC, Kinyamu HK \& Ryschon KL (2001) Caffeine intake increases the rate of bone loss in elderly women and interacts with vitamin D receptor genotypes. Am J Clin Nutr 74, 694-700.

47. Bergman EA, Sherrard DJ \& Massey LK (1987) Effects of dietary caffeine on calcium-metabolism and bone turnover in adult women. Fed Proc 46, 632.

48. Harris S \& Dawson-Hughes B (1994) Caffeine and bone loss in healthy post-menopausal women. J Bone Miner Res $\mathbf{8}$, S261.

49. Ilich JZ, Brownbill RA, Tamborini L \& Crncevic-Orlic Z (2002) To drink or not to drink: how are alcohol, caffeine and past smoking related to bone mineral density in elderly women? J Am Coll Nutr 21, 536-544.

50. Glynn NW, Meilahn EN, Charron M, Anderson SJ, Kuller LH \& Cauley JA (1995) Determinants of bone mineral density in older men. J Bone Miner Res 10, 1769-1777.

51. Hannan MT, Felson DT, Dawson-Hughes B, Tucker KL, Cupples LA, Wilson PWF \& Kiel DP (2000) Risk factors for longitudinal bone loss in elderly men and women: The Framingham osteoporosis study. J Bone Miner Res 15, 710-720.

52. Rico H, Canal ML, Mañas P, Lavado JM, Costa C \& Pedera JD (2002) Effects of caffeine, vitamin D, and other nutrients on quantitative phalangeal bone ultrasound in postmenopausal women. Nutrition 18, 189-193.

53. New SA, Bolton-Smith C, Grubb DA \& Reid DM (1997) Nutritional influences on bone mineral density: a crosssectional study in premenopausal women. Am J Clin Nutr 65, $1831-1839$.

54. Barger-Lux MJ \& Heaney RP (1995) Caffeine and the calcium economy revisited. Osteoporos Int 5, 97-102.

55. Ferrini RL \& Barrett-Connor E (1996) Caffeine intake and endogenous sex steroids levels in post-menopausal women: The Rancho Bernardo study. Am J Epidemiol 144, 642-644.

56. Heaney RP \& Rafferty K (2001) Carbonated beverages and urinary calcium excretion. Am J Clin Nutr 74, 343-347.

57. Yeh JK \& Aloia JF (1986) Differential effect of caffeine administration on calcium and vitamin D metabolism in young and adult rats. J Bone Miner Res 1, 251-258. 
58. Chen X \& Whitford GM (1999) Effects of caffeine on fluoride, calcium and phosphorus metabolism and calcified tissues in the rat. Arch Oral Biol 44, 33-39.

59. Sakamoto W, Nishihira J, Fujie K, Iizuka T, Handa H, Ozaki M \& Yukawa S (2001) Effect of coffee consumption on bone metabolism. Bone 28, 332-336.

60. García-Contreras F, Paniagua R, Avila-Díaz M, CabreraMuñoz L, Martínez-Muñiz I, Foyo-Niembro E \& Amato D (2000) Cola beverage consumption induces bone mineralisation reduction in ovariectomized rats. Arch Med Res 31, 360-365.

61. Heaney RP (2002) Effects of caffeine on bone and the calcium economy. Food Chem Toxicol 40, 1263-1270.

62. Massey LK (2001) Is caffeine a risk factor for bone loss in the elderly? Am J Clin Nutr 74, 569-570.

63. Steinmetz KA \& Potter JD (1996) Vegetables, fruit and cancer prevention: a review. J Am Diet Assoc 96, 1027-1039.

64. Tylavsky FA, Holliday K, Danish R, Womack C, Norwood J \& Carbone L (2004) Fruit and vegetable intakes are an independent predictor of bone size in early pubertal children. Am J Clin Nutr 79, 311-317.

65. Whiting SJ, Vatanparast H, Baxter-Jones A, Faulkner RA, Mirwald R \& Bailey DA (2004) Factors that affect bone mineral accrual in the adolescent growth spurt. $J$ Nutr 134, 696S-700S.

66. McGartland CP, Robson PJ, Murray LJ, Cran GW, Savage MJ, Watkins DC, Rooney MM \& Boreham CA (2004) Fruit and vegetable consumption and bone mineral density: the Northern Ireland young hearts project. Am J Clin Nutr 80, 1019-1023.

67. Chen Y, Ho SC, Lee R, Lam S \& Woo J (2001) Fruit intake is associated with better bone mass among Hong Kong Chinese early postmenopausal women. J Bone Miner Res 16, S386.

68. Tucker KL, Chen H, Hannan MT, Cupples LA, Wilson PWF, Felson D \& Kiel DP (2002) Bone mineral density and dietary patterns in older adults: the Framingham osteoporosis study. Am J Clin Nutr 76, 245-252.

69. Tucker KL, Hannan MT, Chen H, Cupples LA, Wilson PWF \& Kiel DP (1999) Potassium, magnesium, and fruit and vegetable intakes are associated with greater bone mineral density in elderly men and women. Am J Clin Nutr 69, $727-736$.

70. Kaptoge S, Welch A, McTaggart A, Mulligan A, Dalzell N, Day NE, Bingham S, Khaw K-T \& Reeve J (2003) Effects of dietary nutrients and food groups on bone loss from the proximal femur in men and women in the 7 th and 8 th decades of age. Osteoporos Int 14, 418-428.

71. Macdonald HM, New SA, Golden MHN, Campbell MK \& Reid DM (2004) Nutritional associations with bone loss during the menopausal transition: evidence of a beneficial effect of calcium, alcohol, and fruit and vegetable nutrients and of a detrimental effect of fatty acids. Am J Clin Nutr 79, $155-165$.

72. New SA, Robins SP, Campbell MK, Martin JC, Garton MJ, Bolton-Smith C, Grubb DA, Lee SJ \& Reid DM (2000) Dietary influences on bone mass and bone metabolism: further evidence of a positive link between fruit and vegetable consumption and bone health? Am J Clin Nutr 71, 142-151.

73. Tucker KL, Hannan MT \& Kiel DP (2001) The acid-base hypothesis: diet and bone in the Framingham osteoporosis study. Eur J Nutr 40, 231-237.

74. New SA (2002) The role of the skeleton in acid-base homeostasis. Proc Nutr Soc 61, 151-164.

75. Mühlbauer RC, Lozano A \& Reinli A (2002) Onion and a mixture of vegetables, salads, and herbs affect bone resorption in the rat by a mechanism independent of their base excess. J Bone Miner Res 17, 1230-1236.

76. Mühlbauer RC \& Li F (1999) Effect of vegetables on bone metabolism. Nature 401, 343-344.

77. Mühlbauer RC, Lozano A, Reinli A \& Wetli H (2003) Various selected vegetables, fruits, mushrooms and red wine residue inhibit bone resorption in rats. $J$ Nutr 133, 3592-3597.

78. Arjmandi BH, Khalil DA, Lucas EA, Georgis A, Stoecker BJ, Hardin C, Payton ME \& Wild RA (2002) Dried plums improve indices of bone formation in post-menopausal women. J Womens Health and Gend Based Med 11, 61-68.

79. Chiba H, Uehara M, Wu J, Wang X, Masuyama R, Suzuki K, Kanazawa K \& Ishimi Y (2003) Hesperidin, a citrus flavonoid, inhibits bone loss and decreases serum and hepatic lipids in ovariectomized mice. J Nutr 133, 1892-1897.

80. Setchell KDR \& Lydeking-Olsen E (2003) Dietary phytooestrogens and their effect on bone: evidence from in vitro and in vivo, human observational, and dietary intervention studies. Am J Clin Nutr 78, 593S-609S.

81. Branca F (2003) Dietary phyto-oestrogens and bone health. Proc Nutr Soc 62, 877-887.

82. Draper CR, Edel MJ, Dick IM, Randall AG, Martin GB \& Prince RL (1997) Phytoestrogens reduce bone loss and bone resorption in oophorectomized rats. J Nutr 127, 1795-1799.

83. Fanti P, Monier-Faugere MC, Geng Z, Schmidt J, Morris PE, Cohen D \& Malluche HH (1998) The phytoestrogen genistein reduces bone loss in short-term ovariectomized rats. Osteoporos Int 8, 274-281.

84. Lee Y-B, Lee HJ, Kim KS, Le J-Y, Nam SY, Cheon S-H \& Sohn H-S (2004) Evaluation of the preventative effect of isoflavone extract on bone loss in ovariectomized rats. Biosci Biotechnol Biochem 68, 1040-1045.

85. Deyhim F, Stoecker BJ, Brusewitz GH \& Arjmandi BH (2003) The effects of estrogen depletion and isoflavones on bone metabolism in rats. Nutr Res 23, 123-130.

86. Atkinson C, Compston JE, Day NE, Dowsett M \& Bingham SA (2004) The effects of phytoestrogen isoflavones on bone density in women: a double-blind, randomized, placebocontrolled trial. Am J Clin Nutr 79, 326-333.

87. Chen Y-M, Ho SC, Lam SSH, Ho SSS \& Woo JLF (2003) Soy isoflavones have a favorable effect on bone loss in Chinese postmenopausal women with lower bone mass: a double-blind, randomized, controlled trial. J Clin Endocrinol Metab 88, 4740-4747.

88. Kreijkamp-Kaspers S, Kok L, Grobbee DE, de Haan EHF, Aleman A, Lampe JW \& van der Schouw YT (2004) Effect of soy protein containing isoflavones on cognitive function, bone mineral density, and plasma lipids in postmenopausal women: a randomized controlled trial. JAMA 292, 65-74.

89. Melis GB, Paoletti AM \& Cagnacci A (1996) Ipriflavone prevents bone loss in post-menopausal women. Menopause 3, 27-32.

90. Maugeri D, Panebianco P, Russo MS et al. (1994) Ipriflavone-treatment of senile osteoporosis - results of a multicenter, double-blind clinical-trial of 2 years. Arch Gerontol Geriatr 19, 253-263.

91. Yamaguchi M (2002) Isoflavone and bone metabolism: its cellular mechanism and preventative role in bone loss. $J$ Health Sci 48, 209-222.

92. Brouns F \& Vermeer C (2000) Functional food ingredients for reducing the risks of osteoporosis. Trends Food Sci Technol 11, 22-33.

93. Wattanapenpaiboon N, Lukito W, Wahlqvist ML \& Strauss BJG (2003) Dietary carotenoid intake as a predictor of bone mineral density. Asia Pac J Clin Nutr 12, 467-473. 
94. Peterson J, Dwyer J, Bhagwat S, Haytowitz D, Holden J, Eldridge AL, Beecher G \& Aladesanmi J (2005) Major flavonoids in dry tea. J Food Comp Anal 18, 487-501.

95. Astill C, Birch MR, Dacombe C, Humphrey PG \& Martin PT (2001) Factors affecting the caffeine and polyphenol contents of black and green tea infusions. J Agric Food Chem 49, 5340-5347.

96. Clifford MN (1999) Chlorogenic acids and other cinnamates - nature, occurrence and dietary burden. J Sci Food Agric 79, $362-372$.
97. Nebesny E \& Budryn G (2003) Antioxidative activity of green and roasted coffee beans as influenced by convection and microwave roasting methods and content of certain compounds. Eur Food Res Technol 217, 157-163.

98. Debry G (1994) Coffee and Health. Paris: John Libbey Eurotext.

99. Pena A, Lino C \& Silveira MIN (2005) Survey of caffeine levels in retail beverages in Portugal. Food Addit Contam 22, 91-96. 